\title{
دراسة الخصائص النوعية للمياه الجوفية في محافظة كركوك \\ وسبل استثمارها
}

م.م. نفم منصور

جامعة بغداد/ كلية التربية ابن رشد للعلوم الإنسانية

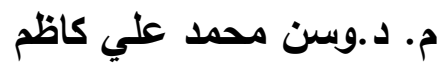

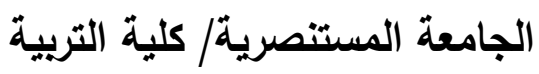

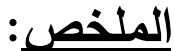

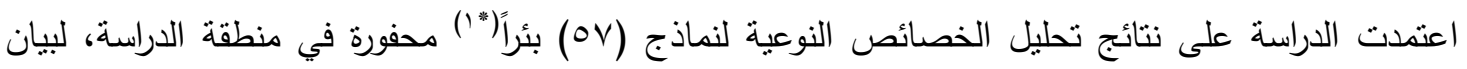

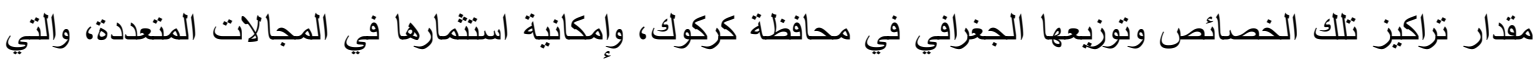
تبين من خلالها أن اغلب نسب التراكيز العالية تقع في قضاء (الحويجة، وداقوق، والمركز). بحيث أن أن أغلبية المياه

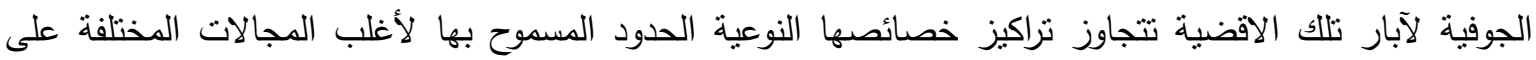

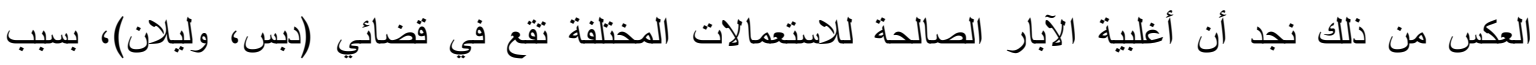

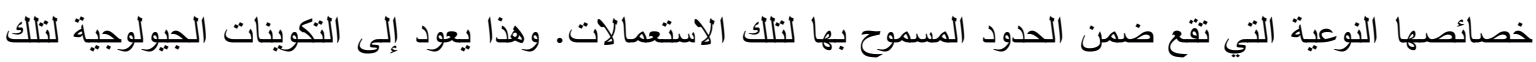

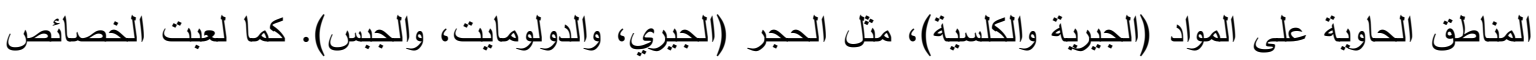

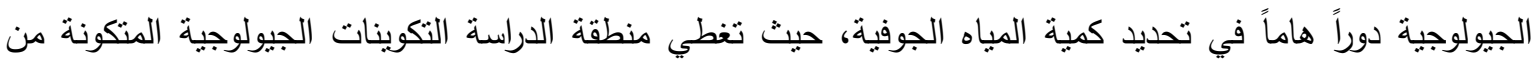

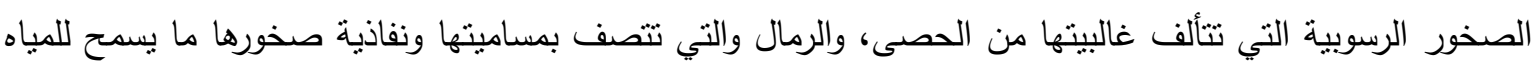

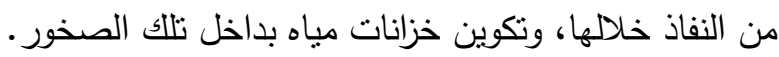

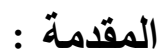

لما أصبح شح المياه ظاهره لا يمكن التغاضي عنها، توجب على الباحثن المختصين في المجالات كافة التي لها علاقة بموضوع المياه، ومنهم الجغرافيين دراسة وبحث سبل حل هذه المشكلة، أو إيجاد البدائل التي تعوض عن أو تسد النقص الحاصل في المياه السطحية، فكان هذا البحث إسهام

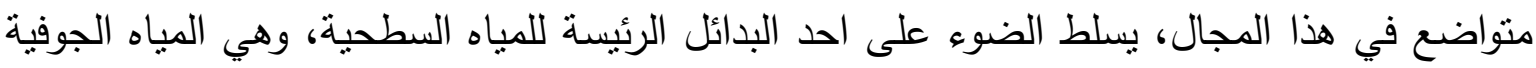

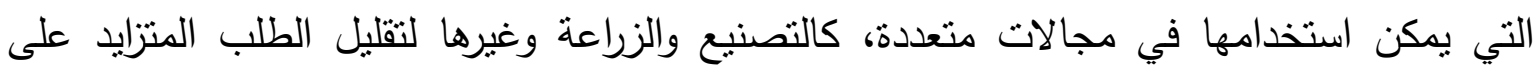

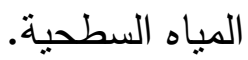

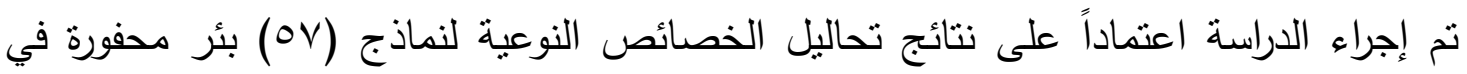
منطقة الدراسة، وكذلك البيانات المستتبطة من الخراط الطبوغرافية والجيولوجية الخاصة بمنطقة الدراسة والتي نوضح نوعية التكوينات الصخرية الخازنة للمباه الجوفية. والبيانات الدناخية المستحصلة من هيئة الأنواء الجوية العراقية، قسم المناخ.

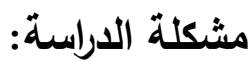

أدى التزايد المستمر لإعداد السكان وزيادة متطلباتهم للشرب والزراعة والصناعة وغيرها، إلى تزايد

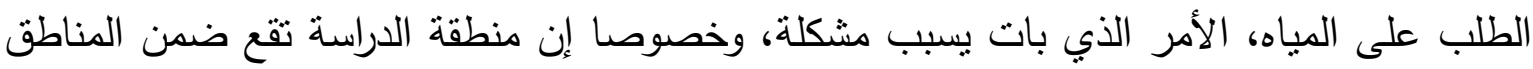


شبه الجافة التي تعاني من نقص في الموارد المائية، لذلك فان هنالك حاجة ماسة لدراسة جميع مصادر المباه للاستفادة منها إلى أقصى حد للإسهام في حل هذه لهورد المشكلة.

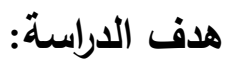

ا ـ دراسة نوعية وكمية المياه الجوفية في محافظة كركوك. r. معرفة مدى صلاحية المياه الجوفية في المحافظة وإمكانية استثمارها للمجالات المتتوعة.

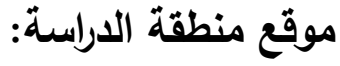
تقع محافظة كركوك في الجزء الثمالي من العراق، ضمن الإقليم الثبه الجبلي بين خطي طول (1) الثمال والثمال الغربي محافظة اربيل ومن جهة الغرب محافظة الموصل ومن جهة الثرق تحدها كل من محافظتي السليمانية وصلاح الدين، وتحدها من الجهة الجنوبية والجنوبية الغربية محافظة صلاح الدين ، كما يظهر في الخريطة (1).

خريطة (1) موقع منطقة الدراسة موضح عليها عينات الآبار المدروسة

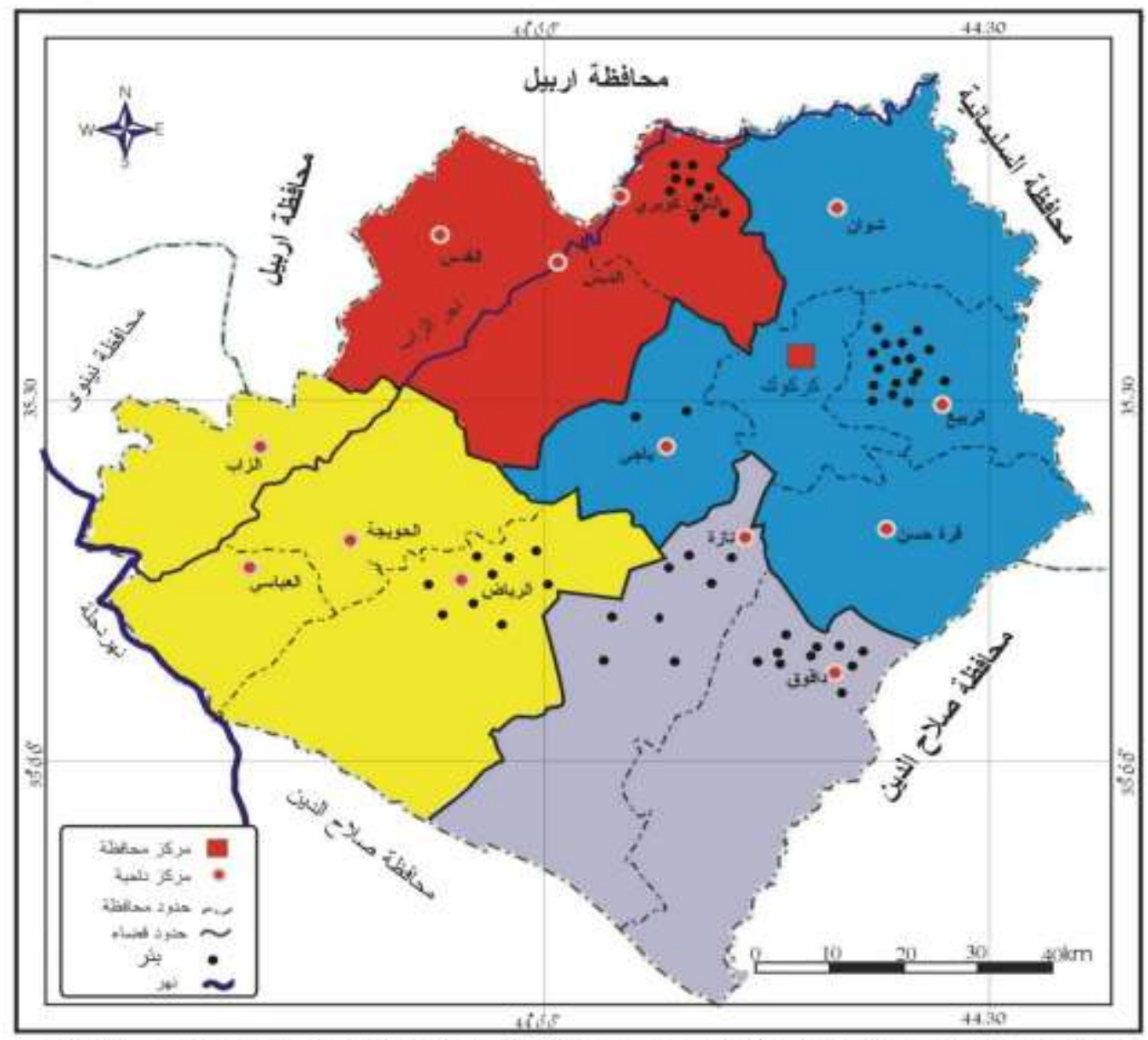

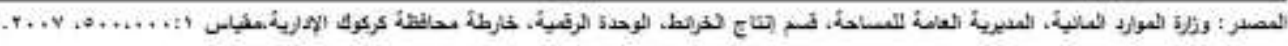


المبحث الأول/ الخصائص الطبيعية لمنطقة الدراسة أولا/ الخصائص الجيولوجية: تؤدي البنية الجيولوجية دوراً رئيساً في توزيع المياه الجوفية وانتشارها، وتحديد خصائصها النوعية والكمية، فهي الوعاء الحامل لتلك المياه الذي يحدد مواقع خزنها، وأعماقها، وامتدادها المساحي، وحركة الماء خلالها، وخصائصها النوعية (صفاتها الكيمائية والفيزيائية)، التي ترتبط جميعاً بنوع الطبقات الصخرية وعمقها. كما أن لمسامية صخور القشرة الأرضية ونفاذيتها دور فعال في تكوين المياه الجوفية، فمن خلال تلك الخاصتين تجد المياه السطحية مسلكاً لتكوين خزانات مياه بداخل هذه الصخور •

تغطي منطقة الدراسة التكوينات الجيولوجية المتكونة من الصخور الرسوبية التي تعود إلى زمنين من حيث القدم، هما الزمن الثالث والرابع، خريطة (r)، وتتألف غالبية تكويناتها من الحصى، والرمال،

خريطة (r) التكويثات الجيولوجية في مثطقة الدراسة

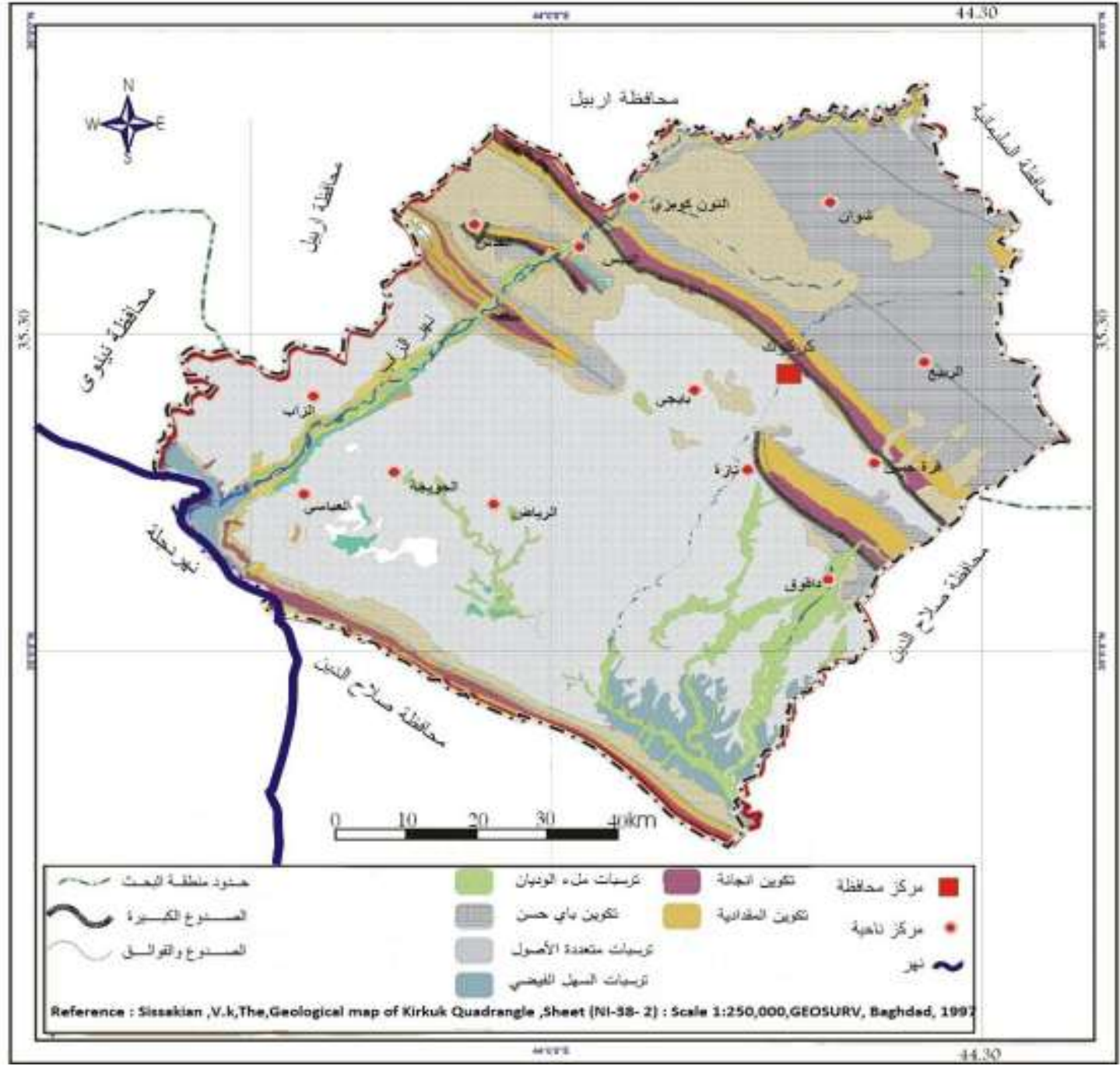


والصلصال، كما يظهر في تكوينات صخور المقطع الجيولوجي لطبقات بعض الآبار المحفورة في منطقة الدراسة، التي تمثل مواقع مختلفة من منطقة الدراسة، شكل ( ()، وهي من حيث القدم كالتالي:

(1) (1)

المقاطع الجيونوجية نطبقات بعض نماذج الآبار المحفورة في منطقة الدراسة

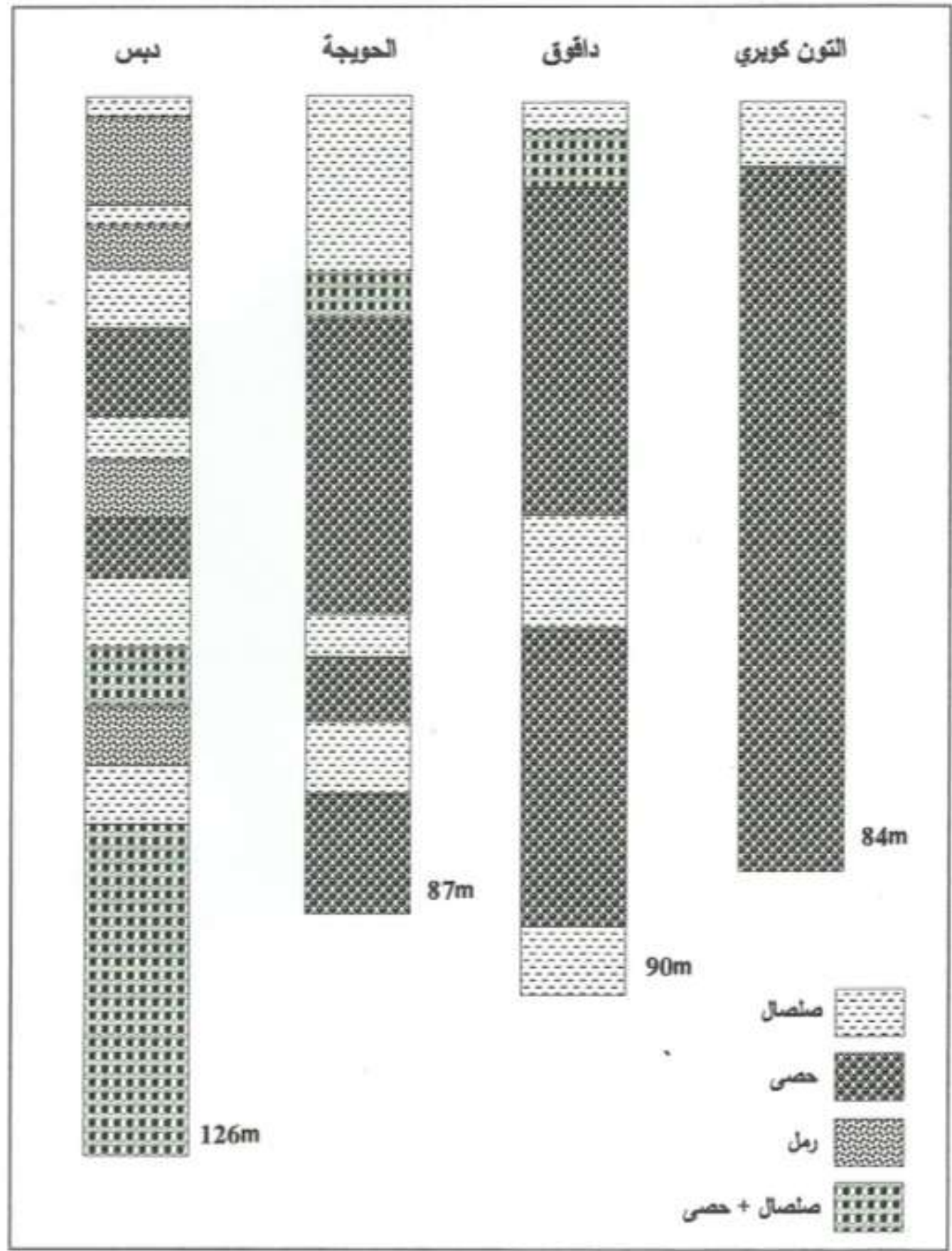

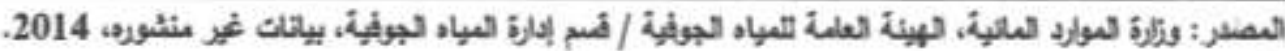


(الفتحة)، نظهر مكاشف هذا التكوين في لب جميع الطيات المحدبة في منطقة الدراسة نقريباً

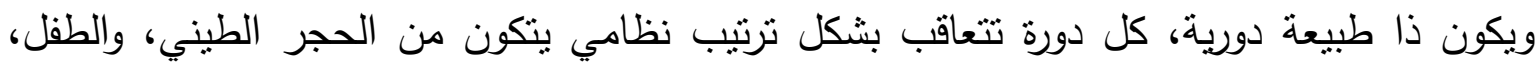

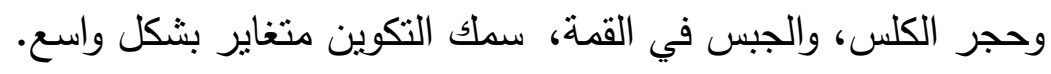

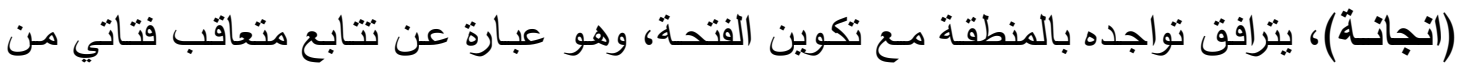

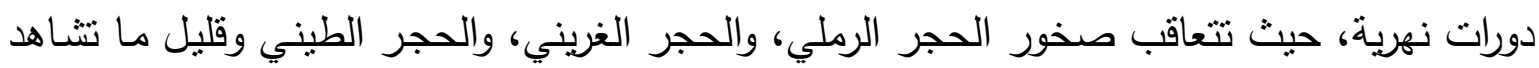

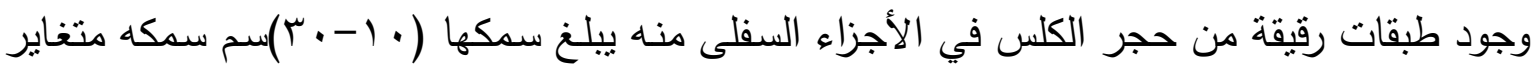

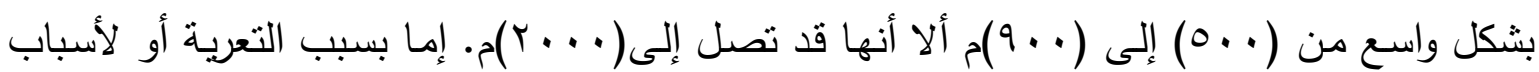

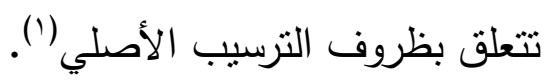
(المقداديـة)، ينكثف التكوين على السطح بصـورة رئيسـة وبشكل واسـع ضمن قطاع الطيات المقعرة المحصورة بين قطاع الطيات العالية، يكون على شكل خط متقطع على حافة أجنحة الطيات.

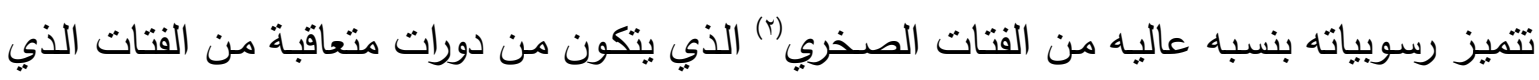

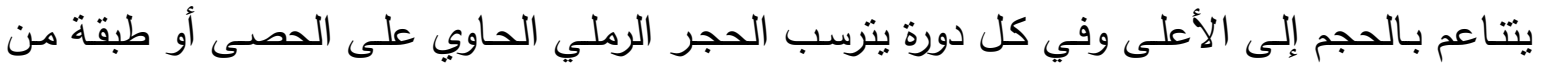

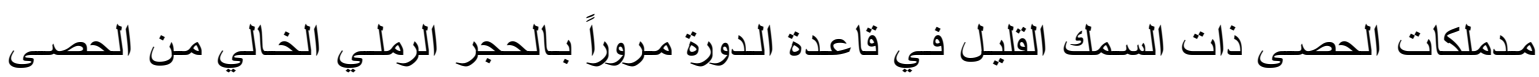
والغرين ثم الحجر الطيني الذي يكون بشكل عدسات كثكل من أثنكال الترسيب(ت).

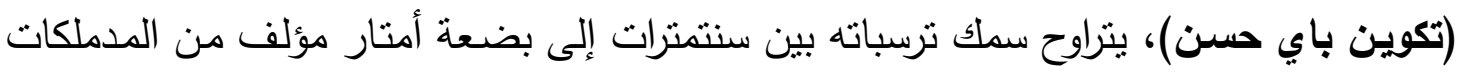

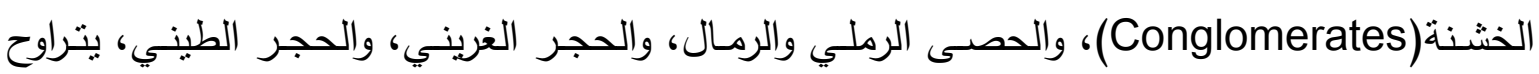

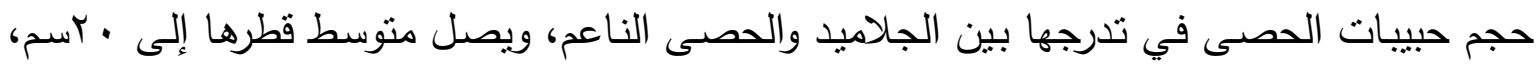

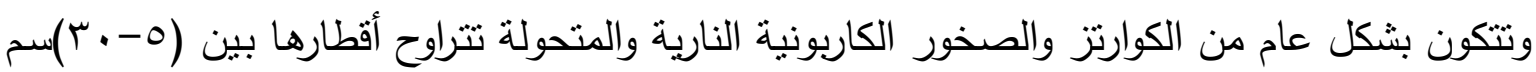
وأحياناً أكثر (ई). ترسبات الزمن (الرابع) العائدة إلى عصري (البلايوستوسين، والهولوسين)، وتغطي معظم مساحة منطقة الدراسة. وتتألف من الرمال والمفتتات الصخرية والجبس الثانوي والطمى والحصى وتتمل: ترسبات متعددة الأصول، (البلايوستوسين-الهولوسين): وتغطي تقريباً نصف منطقة الهنة الدراسة.

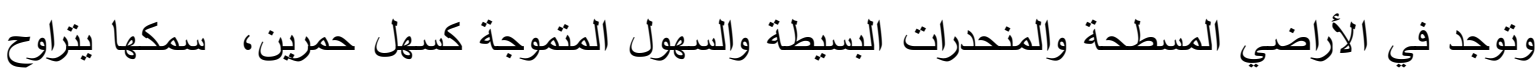

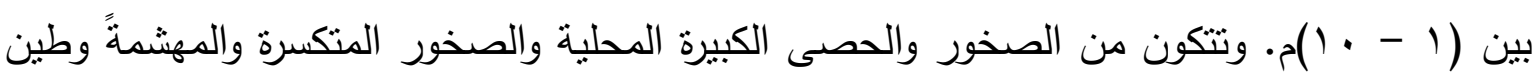
غريني، رملي متماسك، يحتوي على نسبة عالية من الجبس الذي يحتوي على الكالسايت وخليط من الجبس والحديد (0.

ترسبات السهل الفيضي، (الهولوسين): تتجمع هذه الترسبات على شكل أشرطة على بعض

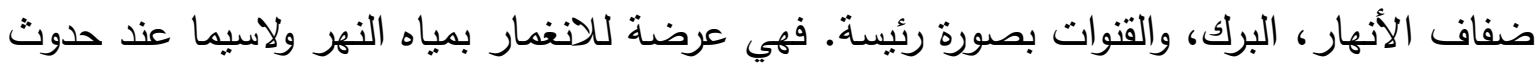
الفيضانات، فتتثكل منها رواسب جديدة تضاف إلى الرواسب القديمة لهذه السهول، وتتألف ترسباتها 
بشكل صفائح وطبقات رقيقة من الرمل الناعم والغرين أما رواسب الفيضانات فتتميز بترسبات الطين

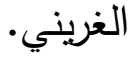

ترسبات ملء الوديان، (الهولوسين): تغطي هذه الترسبات قيعان الوديان، تتكون من نرسبات خشنة كالحصى والفتات الصخري، تتميز ترسبات الوديان في المناطق المنبسطة بتكوّنها بنكل

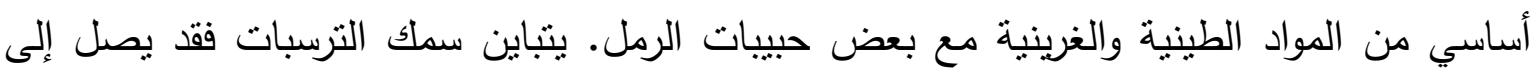

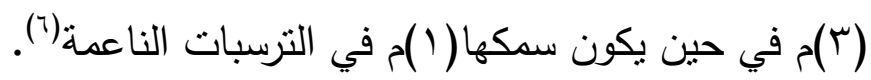
ثانيا / الخصائص المناخية: أهم العناصر المناخية ذات العلاقة بالمياه الجوفية هي، درجة الحرارة والتساقط المطري، وهما

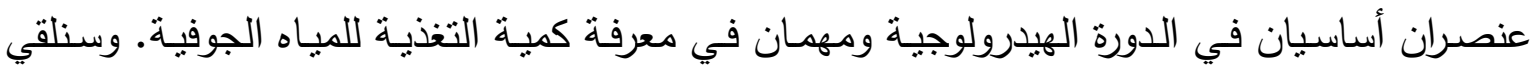
الضوء على هذين العنصرين كالاتي:

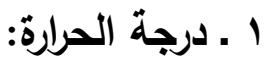

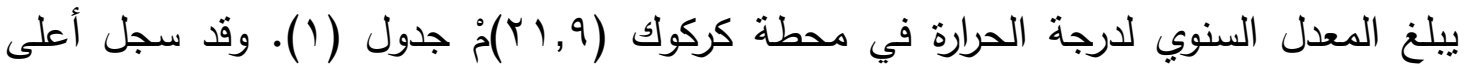
معدل لدرجات الحرارة في شهر (تموز) حيث بلغ (0,0)مْه، وهو ما يرفع من درجة الحرارة في

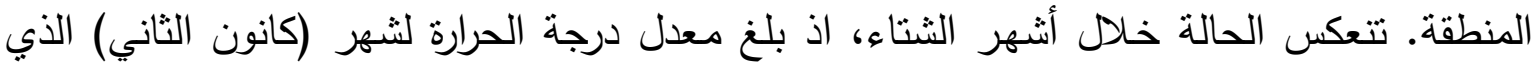

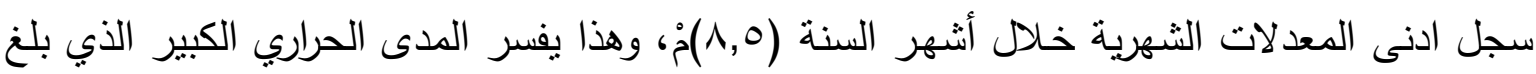
.

يعود سبب هذا التطرف في درجات الحرارة وارتفاع مدياتها اليومية والسنوية فضلاً عن ارتفاع

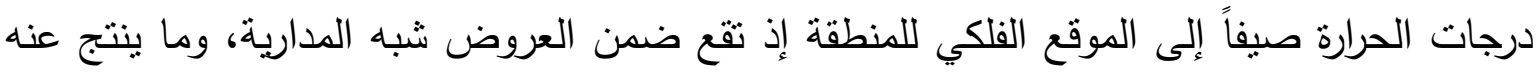
من زيادة زاوية سقوط الإثعاع الثمسي وطول ساعات النهار وكمية الإنشعاع المستلمة خلال النهار التي تكون أكثر من كمية الإشعاع المفقودة خلادل الليل، مما يساعد على وجود تراكم حراري ينجم عنه ارتفاع في درجات الحرارة.

جدول (1) (1) (9)

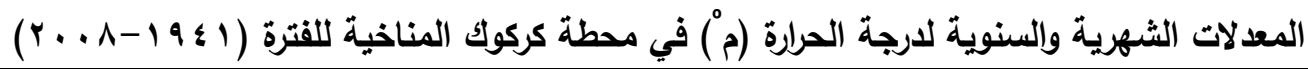

\begin{tabular}{|c|c|c|c|c|c|c|c|c|c|c|c|c|c|}
\hline السنوي & كالون & تثشرين & تشرين & أيلول & آب & تموز & حزيران & مايس & نيسان & آذار & شباط & كانون & المحطة \\
\hline$r 1, q$ & 1,0 & 17,0 & $r\{, r$ & $r \cdot \wedge$ & $r \leqslant, q$ & $r_{0,0}$ & rY, & ד, & 19,4 & 14,9 & $1, r, r$ & $\Lambda, \diamond$ & كركوك \\
\hline
\end{tabular}

المصدر : وزارة العلوم والتكنولوجيا، هيئة الأنواء الجوية العراقية، قسم المناخ، بيانات غير منثورة.

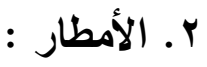

تتباين الأمطار في كمياتها في منطقة الدراسة من سنة إلى أخرى، ونتركز في فصل الثتاء شأنها

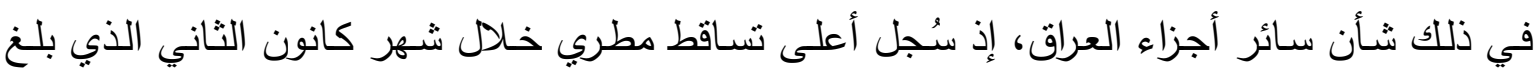




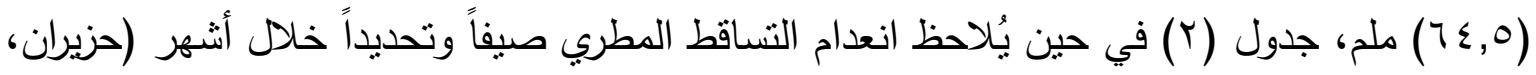

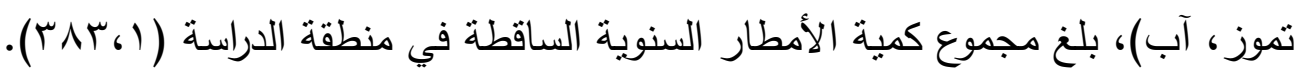

جدول (r) (ب)

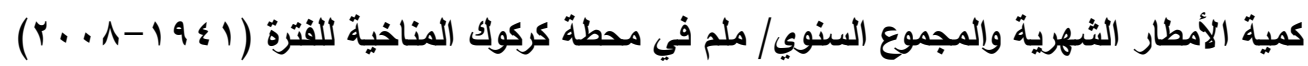

\begin{tabular}{|c|c|c|c|c|c|c|c|c|c|c|c|c|c|}
\hline المجموع & كالأون & تثثرين & تثثرين & أيلول & آب & تموز & حزيلان & مايس & نيسان & آذار & شباط & كانون & المحطة \\
\hline rAT, & צ , . & \& & $\wedge, \wedge$ & $\cdot, r$ & - & - & - & $i v, v$ & $\leqslant 9, \wedge$ & $v \cdot, \wedge$ & $T V, \Lambda$ & $1 \leqslant, 0$ & كركوك \\
\hline
\end{tabular}

الكصدر : وزارة العلوم والنكنولوجيا، هيئة الأنواء الجوية العراقية، قسم المناخ، بيانات غير منشورة.

ثالثا / الخصائص الطبوغرافية : تانية

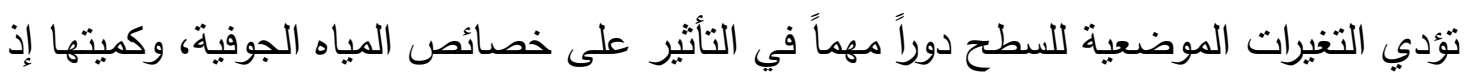

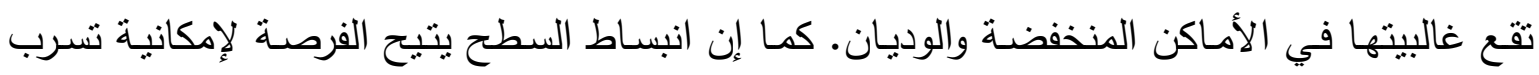

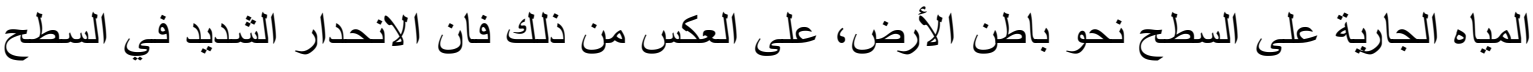
يكون تسرب المياه السطحية فيه ضعيف بسبب سرعة حركتها، هذا وتؤثر سرعة حركة المياه الجوفية في خصائصهـا النوعيـة فكلما كانت السرعة بطيئة كانت المدة الزمنيـة للتبادل الأيوني بين المياه

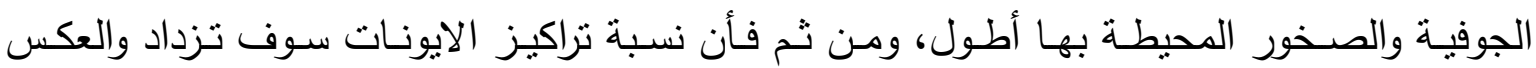

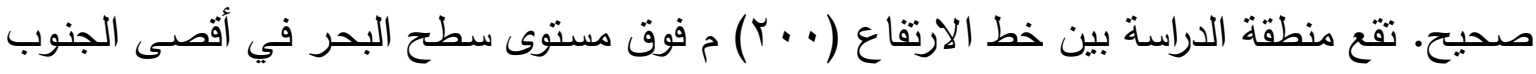

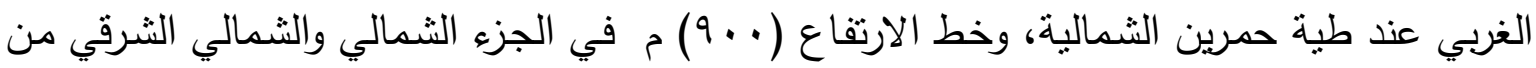

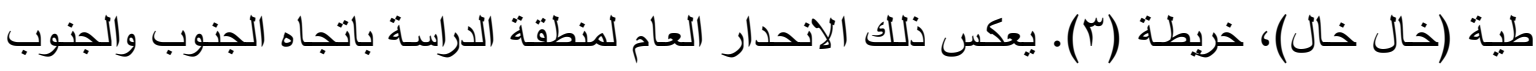
الغربي.

رابعا / خصائص التربة : التربي

لخصائص التربـة أهمية كبيرة، فهي تحدد من خـلال نوعها ونسجتها وبنيتها ونسبة مساميتها ودرجة نفاذيتها مقدار تسرب المياه إلى الطبقات التحت السطحية المغذية للمياه الجوفية. وبذلك لها

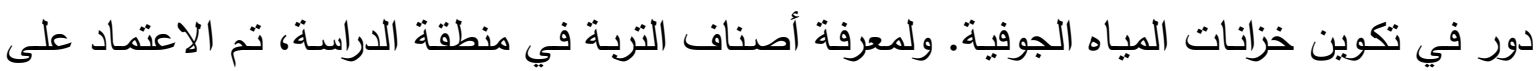

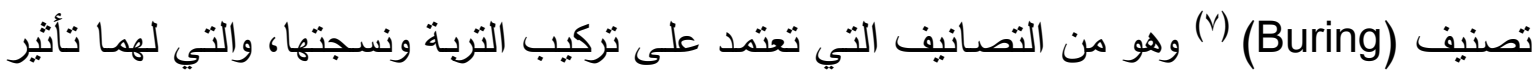
مهم في عملية تسرب المياه. وتتضمن منطقة الدراسة الأصناف التالية من التربة حسب تضاريسها:

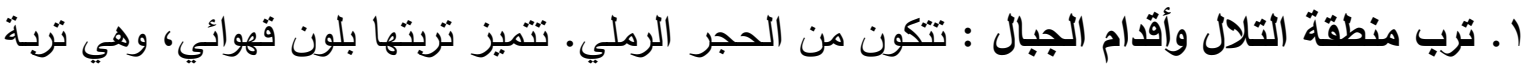
جيدة الصرف، وذات نسجه خشنة إلى متوسطة النعومـة في الطبقة السطحية وناعمة إلى متوسطة النعومة في الطبقة التحتانية. 


\section{خريطة (r) طبوغرافية منطقة الدراسة}

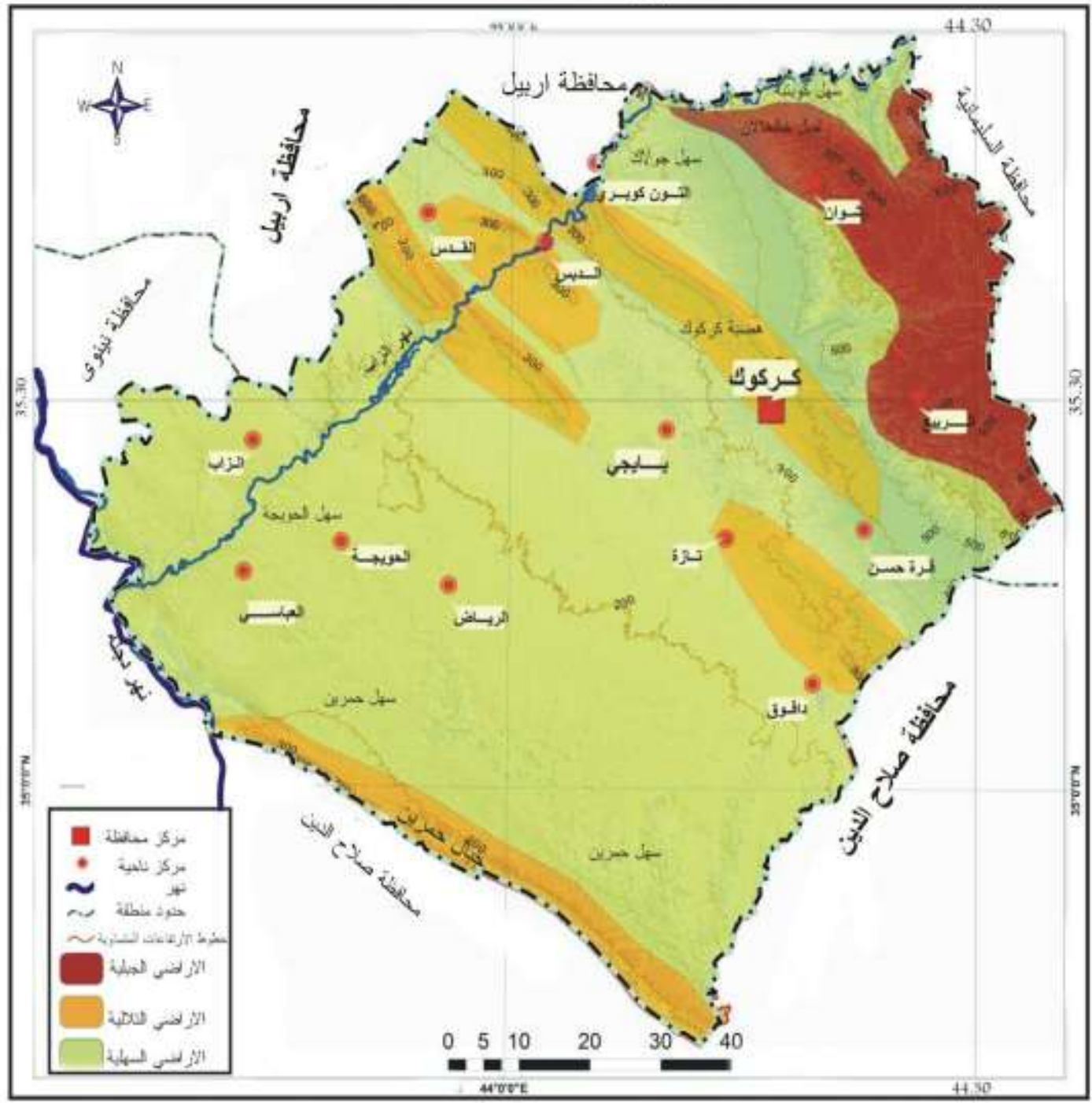

Reference: USGS, "Shuttler Radar Topography Mission.7 arc second scenes", Globai Land Cover Facility, 2007, 8y using ArcGis 9.3 by Surfece Ansilysis

r. تربـة منطقـة السـهول: ناتجـة عن التراكم المستمر للمواد المترسبة من فيضـانات الأنهار عبر

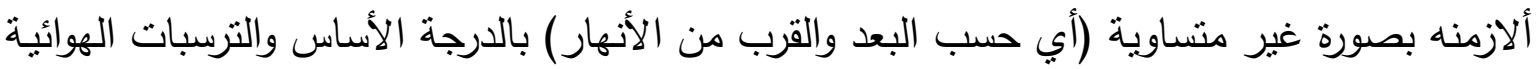
بنسبة اقل. تربتها ذات نسجه متوسطة النعومـة إلى ناعمـة في الطبقة السطحية والتحتانيـة، الدـادة الرئيسة لها هي الغرين والرمل والطين من اصل نهري.

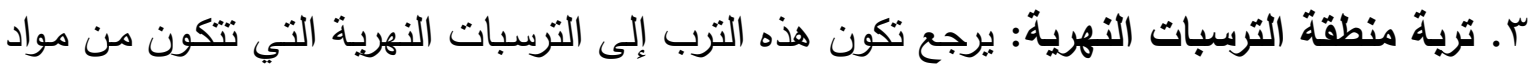

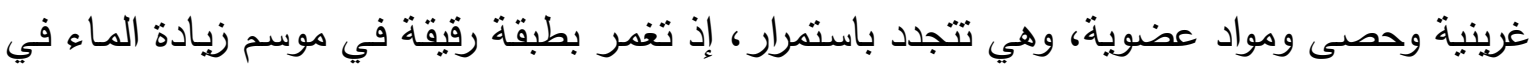
المجرى تاركة طبقة من ترب رسوبية ذات خصوبة عالية وذات نسجه خشنة إلى متوسطة الخشونة في الطبقة السطحية والتحتانية، ذات صرف جيد. 
خامسا/ النبات الطبيعيّ:

تظهر أهمية النبات الطبيعيّ في توافر المياه الجوفية بإعاقة الجريان المائي السطحي ومن ثم زيادة نسبة تسرب مياه الأمطار نحو باطن القترة الأرضية التي تسهم في تغذية الخزين الجوفي.إن توزيع مناطق النبات الطبيعي في العراق يتفق بصورة كبيرة مع المناطق المناخية، وبناءً على ذلك فإن منطقة الدراسة ذات المناخ شبه الجاف تقع ضمن منطقة السهوب. ويتفق حدها الأسفل مع خط المطر ( · . ملم). ويمكن تقيم نباتاتها على قسمين: الأول، نباتات السهوب الجافة التي تتبه نباتات المناطق الصحراوية من حيث تكيفها لفصل الجفاف، واحتوائها على الثجيرات الثوكية والنباتات المعدرة، وتقع ضمن خط المطر ( . . - . . . - ملم وهي تغطي الجهات الجنوبية والجنوبية الغربية لمنطقة الدراسة. واهم نباتاتها الثيح والقيصوم والصمعة، أما الثاني؛ فيثمل نباتات السهوب الرطبة التي تغطي الجهات الثمالية والثمالية الثرقية من منطقة الدراسة، وتتفق مع خط المطر ( . .ب . . . م) ملم وهي أكثر كثافة. وتوجد ضمن حدود هذه المنطقة أشجار الغابات التي تتمو في أعالي الطيات المحدبة، واهم نباتاتها الكعوب والانيمون، أما حشائش السهوب؛ فتوجد على السفوح الواطئة)(ㅅ).

المبحث الثاني/ الخصائص الهيدروليكية والنوعية للمياه الجوفية في منطقة الاراسة هناك خواص تتعلق بالآبار المحفورة والطبقة المائية تظهر في الجدول (ب). يجب إلقاء الضوء عليها قبل الثروع بدراسة الخصائص النوعية للمياه الجوفية وهي: ا ـ الخصائص الهيدروليكية للآبار:

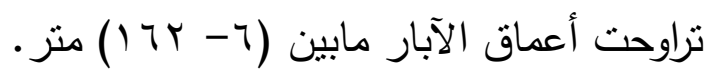

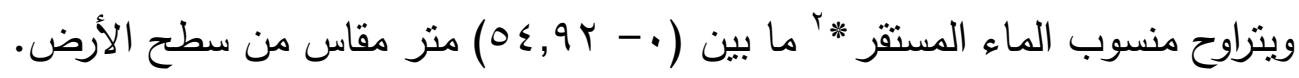

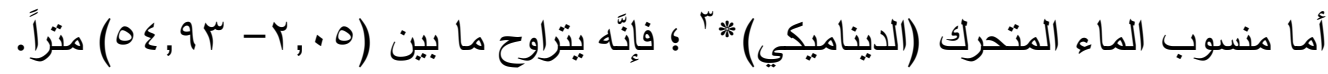

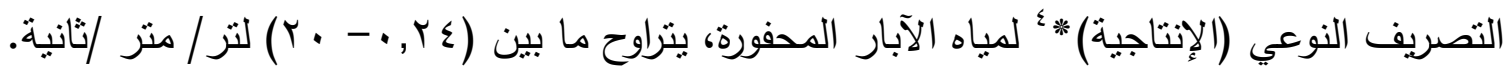
r. الخصائص الهيلروليكية للطبقة المائية:

لم تبين معطيات الآبار الضحلة والعميقة اختلافاً في مناسيب مياهها الجوفية المستقرة، والأدلة على ذلك الآبار المحفورة على أعماق مختلفة في مناطق متعددة من منطقة الدراسـة، وهذا يؤكد فكرة أنَّ الطبقة المائية حرة، وان الاختلاف الحاصل في التكوينات المخترقة ولاسيما سمك الطبقة الطينية الغرينية لم يؤثز هيدروليكيا في نوعية الطبقة المائية بسبب الامتدادات الأفقية الموقعية والعزل غير التام للطبقات المائية أي إن هناك اتصالاً هيدروليكياً بين جميع الطبقات المائية ضمن الحوض الواحد في منطقة الدراسة(9). 
جدول (r)

الخصائص الموقعية والهياروليكية لآبار العينات في محافظة كركوك(")

\begin{tabular}{|c|c|c|c|c|c|c|}
\hline منسوب الماء & منسوب الماء & العقق & الإنتاجية & دائرة العرض & خط الطول & القضاء \\
\hline 48.9 & 46.91 & 140 & 1.6 & $\begin{array}{llll}35 & 35 & 41.5\end{array}$ & $\begin{array}{lll}44 & 21 & 02.1\end{array}$ & دبس \\
\hline 54.93 & 54.92 & 100 & 1 & $\begin{array}{lll}35 & 35 & 46.2\end{array}$ & $44 \quad 21 \quad 27.5$ & دبس \\
\hline 33.64 & 33.36 & 100 & & $\begin{array}{llll}35 & 36 & 33.8\end{array}$ & $\begin{array}{lll}44 & 20 & 29.5\end{array}$ & دبس \\
\hline 52.51 & 52.4 & 100 & 1 & $\begin{array}{lll}35 & 35 & 43.3\end{array}$ & $\begin{array}{lll}44 & 22 & 11.8\end{array}$ & دبس \\
\hline 52.51 & 52.4 & 95 & & $\begin{array}{lll}35 & 35 & 11.4\end{array}$ & $\begin{array}{lll}44 & 22 & 11.4\end{array}$ & دبس \\
\hline \multirow[t]{7}{*}{52.27} & 52.14 & 100 & 1 & $\begin{array}{lll}35 & 35 & 51.7\end{array}$ & $\begin{array}{lll}44 & 22 & 06.8\end{array}$ & دبس \\
\hline & & 150 & 2 & $\begin{array}{lll}35 & 36 & 38.3\end{array}$ & $\begin{array}{lll}44 & 22 & 16.5\end{array}$ & دبس \\
\hline & & 150 & & $\begin{array}{lll}35 & 38 & 57.5\end{array}$ & $\begin{array}{lll}44 & 23 & 22.2\end{array}$ & دبس \\
\hline & & 42 & & $\begin{array}{lll}35 & 38 & 36.9\end{array}$ & $\begin{array}{lll}44 & 18 & 55.2\end{array}$ & دبس \\
\hline & & 120 & 7 & $\begin{array}{lll}35 & 20 & 22\end{array}$ & $\begin{array}{lll}44 & 04 & 01\end{array}$ & الحويجة \\
\hline & & 150 & 10 & $\begin{array}{lll}35 & 18 & 55 \\
\end{array}$ & $\begin{array}{lll}44 & 01 & 23 \\
\end{array}$ & الحويجة \\
\hline & & 10 & 1 & $\begin{array}{lll}35 & 14 & 40\end{array}$ & $\begin{array}{lll}43 & 57 & 53\end{array}$ & الحويجة \\
\hline 9 & 4 & 162 & 12 & $\begin{array}{lll}35 & 15 & 22\end{array}$ & $\begin{array}{lll}43 & 55 & 41\end{array}$ & الحويجة \\
\hline \multirow[t]{4}{*}{10.27} & 7.66 & 45 & 4 & $\begin{array}{lll}35 & 22 & 26 \\
\end{array}$ & $\begin{array}{|lll|}43 & 56 & 11 \\
\end{array}$ & الحويجة \\
\hline & & 6 & 2 & $\begin{array}{lll}35 & 17 & 45 \\
\end{array}$ & $\begin{array}{lll}44 & 00 & 23 \\
\end{array}$ & الحويجة \\
\hline & & 100 & 10 & $\begin{array}{lll}35 & 15 & 20\end{array}$ & $\begin{array}{lll}43 & 57 & 20\end{array}$ & الحويجة \\
\hline & & 130 & & $\begin{array}{lll}35 & 21 & 29 \\
\end{array}$ & $\begin{array}{lll}43 & 50 & 34 \\
\end{array}$ & الحويجة \\
\hline \multirow[t]{3}{*}{76.47} & 71.22 & 120 & & $\begin{array}{lll}35 & 21 & 21 \\
\end{array}$ & $\begin{array}{lll}43 & 50 & 45 \\
\end{array}$ & الحويجة \\
\hline & & 160 & & $\begin{array}{lll}35 & 09 & 58 \\
\end{array}$ & $\begin{array}{lll}44 & 06 & 10 \\
\end{array}$ & داقوق \\
\hline & 5.44 & 30 & 0.5 & $\begin{array}{lll}35 & 20 & 16.5\end{array}$ & $\begin{array}{lll}44 & 17 & 44\end{array}$ & داقوق \\
\hline 14.6 & 8.12 & 40 & 1.50 & $\begin{array}{lll}35 & 21 & 13.2 \\
\end{array}$ & $\begin{array}{lll}44 & 18 & 52.5 \\
\end{array}$ & داقوق \\
\hline 13.2 & 8.55 & 42 & 1 & $\begin{array}{lll}35 & 21 & 12.6 \\
\end{array}$ & $\begin{array}{lll}44 & 18 & 55.6 \\
\end{array}$ & داقوق \\
\hline 11.3 & 5.9 & 51 & 0.5 & $\begin{array}{lll}35 & 21 & 02.3 \\
\end{array}$ & $\begin{array}{lll}44 & 18 & 27.0 \\
\end{array}$ & داقوق \\
\hline 32 & 31 & 80 & 7 & $\begin{array}{lll}35 & 09 & 33.2 \\
\end{array}$ & $\begin{array}{lll}44 & 26 & 35.7 \\
\end{array}$ & داقوق \\
\hline \multirow[t]{2}{*}{32} & 30 & 95 & 15 & $\begin{array}{llll}35 & 09 & 33.0 \\
\end{array}$ & $\begin{array}{lll}44 & 28 & 05.9 \\
\end{array}$ & داقوق \\
\hline & 18 & 120 & 20 & $\begin{array}{lll}35 & 08 & 08.6 \\
\end{array}$ & $\begin{array}{lll}44 & 22 & 18.6 \\
\end{array}$ & داقوق \\
\hline 11.2 & 5.58 & 110 & 5 & $\begin{array}{lll}35 & 21 & 29.4 \\
\end{array}$ & $\begin{array}{lll}44 & 16 & 00.6 \\
\end{array}$ & داقوق \\
\hline \multirow[t]{10}{*}{16} & 13 & 72 & 10 & $\begin{array}{lll}35 & 04 & 23.2 \\
\end{array}$ & 443006.9 & داقوق \\
\hline & 40 & 102 & 20 & 350822.8 & 442852.3 & داقوق \\
\hline & 42 & 67 & 15 & 350846.6 & 442914.8 & داقوق \\
\hline & 30 & 80 & 20 & 350904.1 & 442735.6 & داقوق \\
\hline & 30 & 100 & 13 & 350852.4 & 442648.7 & داقوق \\
\hline & 20 & 90 & 20 & 345936.5 & 443047.4 & داقوق \\
\hline & 6 & 120 & 9 & & & داقوق \\
\hline & 6 & 90 & 9 & & & داقوق \\
\hline & & 100 & 12 & & & داقوق \\
\hline & & 120 & 15 & $\begin{array}{lll}35 & 14 & 55.9\end{array}$ & $\begin{array}{lll}44 & 22 & 46.0\end{array}$ & المركز \\
\hline 29.3 & 28.78 & 80 & 0.95 & $\begin{array}{lll}35 & 23 & 54.9 \\
\end{array}$ & $\begin{array}{lll}44 & 26 & 19.2 \\
\end{array}$ & المركز \\
\hline
\end{tabular}




\begin{tabular}{|c|c|c|c|c|c|c|}
\hline 10 & 7 & 92 & 15 & $\begin{array}{lll}35 & 22 & 38.1\end{array}$ & $\begin{array}{lll}44 & 14 & 35.0\end{array}$ & المركز \\
\hline 26.5 & 14.91 & 54.5 & 0.84 & $\begin{array}{lll}35 & 15 & 13.0\end{array}$ & $\begin{array}{lll}44 & 23 & 39.0\end{array}$ & المركز \\
\hline 17 & 13.95 & 60 & 1.2 & $\begin{array}{lll}35 & 15 & 20.2\end{array}$ & $\begin{array}{lll}44 & 23 & 41.9\end{array}$ & المركز \\
\hline 14 & 6 & 125 & 10 & $\begin{array}{lll}35 & 22 & 11.8\end{array}$ & $\begin{array}{lll}44 & 14 & 52.6\end{array}$ & المركز \\
\hline 16 & 16.41 & 82 & 0.7 & & & المركز \\
\hline \multirow[t]{2}{*}{26.4} & 25.05 & 101 & 1 & $35 \quad 2409$ & $\begin{array}{lll}44 & 26 & 33.6\end{array}$ & المركز \\
\hline & & 120 & 1.5 & $\begin{array}{lll}35 & 22 & 36.1\end{array}$ & $44 \quad 2650.0$ & المركز \\
\hline \multirow[t]{3}{*}{52.87} & 48.75 & 120 & 4 & & & ليلان \\
\hline & & --- & --- & & & ليلان \\
\hline & & 67 & 1 & & & ليلان \\
\hline 2.05 & 1.8 & 6 & 2 & & & ليلان \\
\hline 43.8 & 41.08 & --- & 4 & & & ليلان \\
\hline \multirow[t]{2}{*}{11.65} & 10.78 & 20 & 1 & & & ليلان \\
\hline & 19.69 & 24 & --- & & & ليلان \\
\hline 21.11 & 17.76 & 24 & 0.81 & & & ليلان \\
\hline 14.12 & 13.82 & 24 & 0.24 & & & ليلان \\
\hline
\end{tabular}

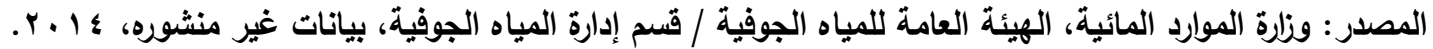
(") النقص في بيانات بعض الآبار المحفورة يعود إلى عدم توفرها في الهيئة العامة للمياه الجوفية مصدر تلكاد البيانات.

r. الخصائص النوعية للمياه الجوفية:

نبحث في هذه الخصـائص للتعرف على مدى صــلاحية الميـاه للأغراض البشـرية المتعددة

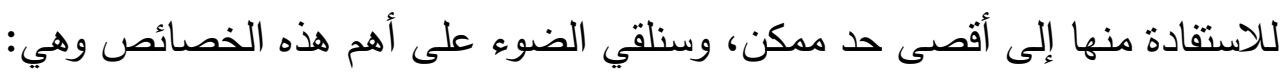
أولا / الأس الهيروجيني (درجة تركيز أيون الهيدروجين pH) :

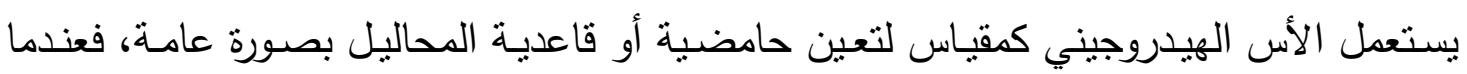

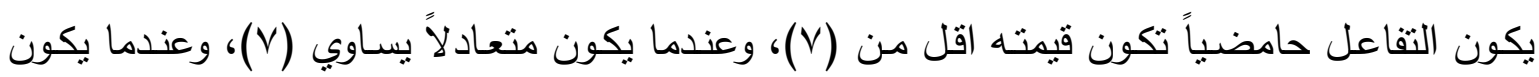

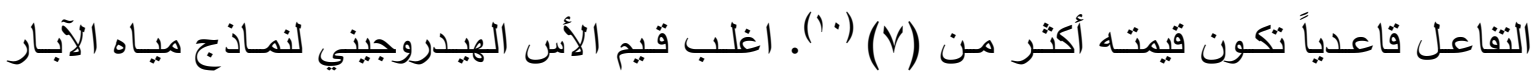

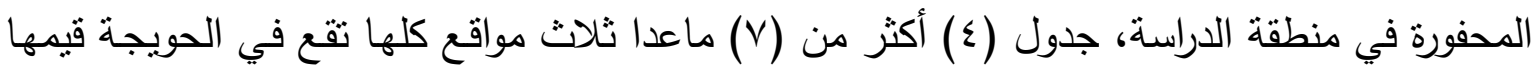

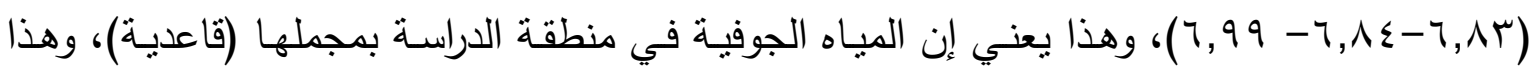

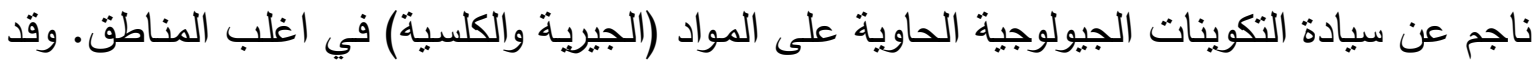

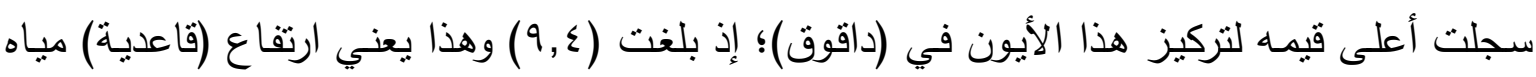
هذا الموقع، ويرجع ذلك إلى نثاط عمليات الإذابة للصخور (الجيرية، والدولوماتية، والكلسية). 
جدول (؛) الخصائص النوعية لعينات الآبار في محافظة كركوك(")

\begin{tabular}{|c|c|c|c|c|c|c|c|c|c|c|c|}
\hline $\begin{array}{c}\text { نترات } \\
\text { NO3 } \\
\text { (ppm) }\end{array}$ & $\begin{array}{l}\text { بيكاريونات } \\
\text { HCO3 } \\
\text { (ppm) }\end{array}$ & $\begin{array}{l}\text { كبريتات } \\
\text { so4 } \\
\text { (ppm) }\end{array}$ & $\begin{array}{c}\text { الكلور } \\
\text { Cl } \\
\text { (ppm) }\end{array}$ & $\begin{array}{c}\text { الكالسيوم Ca } \\
\text { (ppm) }\end{array}$ & $\begin{array}{c}\text { المتيسيوم } \\
\text { Mg } \\
\text { (ppm) }\end{array}$ & $\begin{array}{c}\text { الصوديوم } \\
\text { Na } \\
\text { (ppm) }\end{array}$ & $\begin{array}{l}\text { البوتاسي } \\
\text { K } 1 \text { وpm) }\end{array}$ & $\begin{array}{c}\text { الذائبة } \\
\text { المواد } \\
\text { TDS } \\
\text { (ppm) }\end{array}$ & $\begin{array}{c}\text { الكهريائية } \\
\text { EC } \\
\text { ( } \mathbf{\mu s} / \mathrm{cm})\end{array}$ & $\begin{array}{l}\text { الهيدرج } \\
\text { Ph }\end{array}$ & $\begin{array}{l}\overline{1} \\
\overline{3} \\
.2\end{array}$ \\
\hline 0.9 & 109.8 & 96 & 11 & 56.1 & 39 & 73 & 1.2 & 400 & 794 & 8.06 & \\
\hline 2.3 & 146.4 & 57.6 & 21.2 & 48 & 19.4 & 57.7 & 2.3 & 384 & 566 & 8.48 & \\
\hline 3.2 & 134.2 & 38.4 & 21.2 & 44 & 31.6 & 25.4 & 1.6 & 329 & 543 & 8.22 & \\
\hline 3 & 36.6 & 57.6 & 10.6 & 32 & 9.7 & 44.8 & 1.9 & 210 & 446 & 8.11 & \\
\hline 3.08 & 61.01 & 38.4 & 21.27 & 40.08 & 21.8 & 45.1 & 1.8 & 246 & 447 & 8.06 & \\
\hline 3.76 & 48.8 & 48 & 21.2 & 36.07 & 17 & 61 & 1.9 & 250 & 473 & 8.31 & \\
\hline 2.96 & 73 & 28.8 & 10.6 & 44.08 & 14.5 & 52.4 & 2.2 & 253 & 405 & 8.13 & \\
\hline 3.2 & 134.2 & 96.0 & 21.2 & 40 & 29.1 & 26.9 & 1.5 & 384 & 434 & 7.98 & \\
\hline 3.6 & 134.2 & 86.4 & 21.2 & 56.1 & 36.4 & 32.9 & 1.7 & 398 & 504 & 8.06 & \\
\hline 51.3 & 195.2 & 163.3 & 510.6 & 224.4 & 189.6 & 660 & 5.8 & 3750 & 4862 & 7.63 & \\
\hline 3 & 183 & 883.7 & 106.3 & 336.6 & 116.7 & 216 & 9.8 & 1908 & 2672 & 7.69 & \\
\hline 7.56 & 109.8 & 2017 & 1489 & 440.8 & 340.4 & 801 & 7.6 & 5350 & 7687 & 6.84 & \\
\hline 80 & 219.6 & 1200 & 1064 & 601.2 & 364.8 & 786 & 9 & 4380 & 7900 & 7.46 & \\
\hline 0.52 & 109.8 & 96 & 42.5 & 72.1 & 55.9 & 40.9 & 1.9 & 593 & 669 & 6.99 & $\bar{\gamma}$ \\
\hline 5.04 & 183 & 1114 & 297.8 & 480.9 & 243.2 & 368 & 4.5 & 2770 & 4147 & 7.6 & \\
\hline 9 & 195.2 & 1067 & 372.3 & 360.7 & 340.4 & 590 & 5.2 & 2970 & 5258 & 6.83 & \\
\hline 4 & 207.4 & 307.3 & 170.2 & 160.3 & 9.7 & 299 & 3.9 & 1218 & 2048 & 7.55 & \\
\hline 4.72 & 219.6 & 2161 & 1064 & 521 & 291.8 & 885 & 9.5 & 5185 & 8440 & 7.59 & \\
\hline 1.4 & 61.1 & 768.4 & 127.6 & 513 & 175.1 & 209 & 7 & 2000 & 3572 & 9.4 & \\
\hline 4.12 & 256 & 960.6 & 128 & 409 & 238 & 427 & 3.4 & 2400 & 4375 & 7.39 & \\
\hline 2.76 & 219.6 & 1018 & 127.6 & 400.8 & 262.6 & 356 & 3.9 & 2725 & 4004 & 7.46 & \\
\hline 2.15 & 207 & 292 & 43 & 152 & 34 & 26.4 & 3.1 & 814 & 1038 & 7.43 & \\
\hline 1.28 & 109.8 & 57.6 & 21.2 & 72.1 & 38.9 & 72.9 & 3.2 & 407 & 881 & 7.82 & \\
\hline 0.44 & 219.6 & 134.4 & 63.8 & 64.1 & 53.5 & 101 & 4.7 & 708 & 946 & 7.89 & \\
\hline 2.36 & 378.2 & 614.7 & 42.5 & 224.4 & 155.6 & 227 & 4.7 & 1685 & 2430 & 7.5 & \\
\hline 2.88 & 244 & 691.6 & 212.7 & 513 & 311 & 315 & 3.8 & 2400 & 4427 & 7.73 & \\
\hline 1.84 & 183 & 172.9 & 42.5 & 128.2 & 53.5 & 101 & 4.2 & 711 & 1194 & 7.59 & : \\
\hline 1.96 & 146.4 & 96 & 21.2 & 32 & 34 & 86.3 & 3.9 & 463 & 793 & 8.05 & \\
\hline 1.08 & 97.6 & 163.3 & 21.2 & 80.1 & 34 & 66.9 & 5 & 489 & 756 & 7.65 & \\
\hline 1 & 109.8 & 76.8 & 21.2 & 72.1 & 19.4 & 57.1 & 4.2 & 413 & 628 & 7.64 & \\
\hline 1.6 & 146.4 & 326.6 & 170.4 & 200.4 & 82.6 & 276 & 6.5 & 1238 & 2229 & 7.94 & \\
\hline 0.64 & 109.2 & 960.6 & 212.7 & 480.9 & 145.9 & 457 & 7 & 2409 & 4069 & 8.25 & \\
\hline 0.28 & 97.6 & 537.9 & 42.5 & 240.4 & 272.3 & 296 & 5.1 & 1545 & 2936 & 8.11 & \\
\hline 1 & 109.8 & 96.0 & 212.7 & 120.2 & 77.8 & 156 & 3.2 & 820 & 1437 & 7.64 & \\
\hline 1.12 & 97.6 & 76.8 & 42.5 & 104.2 & 9.7 & 56.4 & 3.5 & 443 & 876 & 8.7 & \\
\hline 1.2 & 219.6 & 307.3 & 63.8 & 128.2 & 136.1 & 260 & 3.8 & 1188 & 2298 & 7.87 & \\
\hline
\end{tabular}




\begin{tabular}{|c|c|c|c|c|c|c|c|c|c|c|c|}
\hline 5.6 & 134 & 1748 & 191.5 & 384.8 & 175 & 360 & 5.5 & 3035 & 3877 & 7.7 & ال \\
\hline 0.64 & 183 & 537.9 & 127.6 & 208.4 & 252.9 & 185 & 4.3 & 1510 & 2314 & 7.9 & مرك \\
\hline 8.1 & 170 & 290 & 43 & 104 & 88 & 254 & 3.7 & 994 & 1678 & 8 & j \\
\hline 4.56 & 170 & 518.7 & 43 & 72 & 63 & 287 & 4.2 & 1180 & 1572 & 7.87 & \\
\hline 2.64 & 378.2 & 461.0 & 127.6 & 240.4 & 243.2 & 246 & 3.5 & 1795 & 3084 & 7.98 & \\
\hline 1.1 & 146.6 & 499 & 64 & 72 & 63 & 278 & 3.8 & 1166 & 1532 & 8.1 & \\
\hline 4.75 & 122 & 1479 & 149 & 400.8 & 116.7 & 260 & 8 & 2568 & 3581 & 7.44 & \\
\hline 4.4 & 146 & 1057.0 & 106 & 80 & 160.5 & 256.1 & 4.1 & 1956 & 2118 & 7.5 & \\
\hline 0.92 & 183 & 240 & 53 & 72 & 63.2 & 56.9 & 2.8 & 698 & 932 & 7.75 & \\
\hline 3.2 & 85.4 & 86.4 & 42.5 & 48 & 24.3 & 33.8 & 2 & 388 & 547 & 7.88 & \\
\hline 2.6 & 97.6 & 28.8 & 42.5 & 36 & 21.8 & 30.5 & 2.1 & 291 & 386 & 7.97 & \\
\hline 2.28 & 97.6 & 28.8 & 43 & 40 & 19.4 & 29.4 & 2.1 & 324 & 425 & 7.93 & \\
\hline 3.4 & 219.6 & 499 & 85.1 & 144.2 & 77.8 & 227 & 2.1 & 1305 & 1845 & 7.62 & ]. \\
\hline 1.68 & 170.8 & 642.4 & 85.1 & 216.4 & 112 & 255 & 2.4 & 1580 & 2477 & 7.72 & \\
\hline 6.04 & 170 & 384.2 & 170.2 & 144.2 & 97 & 121 & 4.6 & 1125 & 1633 & 7.78 & \\
\hline 3.44 & 195.2 & 192 & 85 & 64.1 & 58.3 & 133.6 & 2.5 & 815 & 1040 & 7.72 & \\
\hline 5.44 & 170.8 & 518.7 & 191.4 & 128.2 & 126.4 & 368 & 4.8 & 1593 & 2514 & 7.7 & \\
\hline
\end{tabular}

المصدر: وزارة الموارد المائية، الهيئة العامة للمياه الجوفية / قسم إدارة المياه الجوفية، بيانات غير منشوره، ؛ ا ـ ؟.

\section{Electric Conductivity * *نانيا/ التوصيل الكهريائي}

يُعد التوصيل الكهربائي مقياسـاً لتركيز مجموع (الأيونـات) المكونـة للأمـلاح الذائبة، وكلما زادت الأملاح الذائبة كان التوصبل الكهربائي للمحلول أكبر ('). لقد بينت نتائج التحاليل لجميع نماذج مياه الآبار المحفورة في منطقة الدراسة ومن خلال ملاحظة الجدول (ع) أن اغلب قيم التوصيلة الكهربائية فيها أقل من ( . . (0) ميكروموز/سم، ويشذ عن هذه القاعدة عدد محدود من نماذج مياه الآبار . أعلى

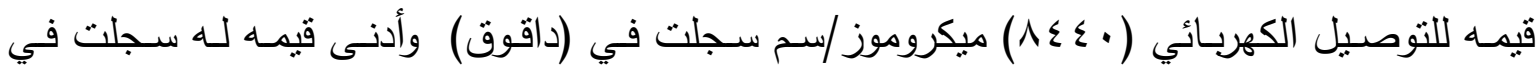

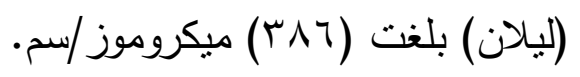

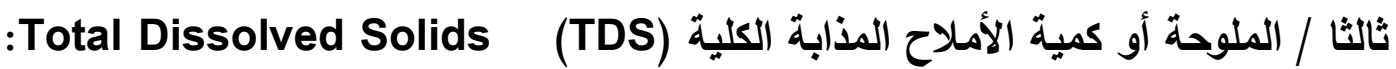
مؤشر أخر لمقدار نملح المياه، وتستخدم نسبها للتعرف على مقدار تحمل المحاصيل للأملاح. أن تركيز الـ(TDS) نتاج بيئة المنطقة، ونوعية الصخور الحاملة للمياه وسرعة حركة المياه الجوفية فكلما كانت السرعة بطيئة كانت ألمده الزمنية للتبادل الأيوني بين المياه الجوفية والصخور المحيطة بها أطول، وبالتالي فأن نسبة أل(TDS) في المياه سوف تزداد. كما لا يمكن الفصل بين كمية الأملاح المذابة الكلية (TDS) والتوصيل الكهربائي عند دراسة خواص المياه الجوفية فكلاهما مقياس لكمية الأملاح الذائبة بالمياه وهذا بظهر بشكل واضتح في الجدول (ع) للتوزيع الجغرافي لقيم كل من الـ(TDS) والتوصيلة الكهربائية على حدً سواء، حيث يتشابه التوزيع الجغرافي لقيم كل منهما. سجلت 


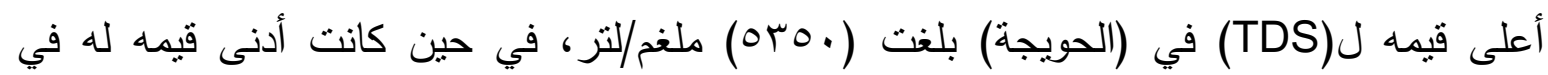

$$
\begin{aligned}
& \text { (دبس) وبلغت (• إY) ملغم/لتز . } \\
& \text { رابعا/ الايونات: }
\end{aligned}
$$

1. (أيون الكالسيوم (Calcium Ca+2):

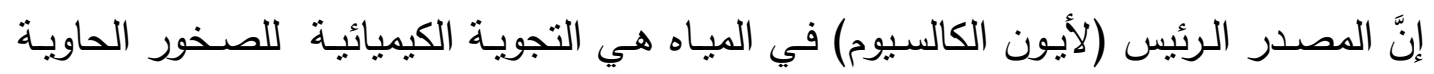

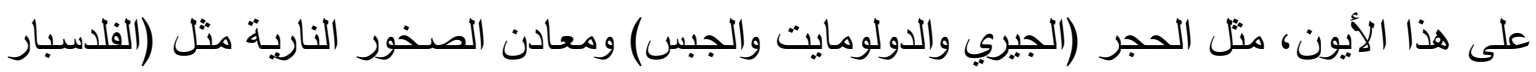

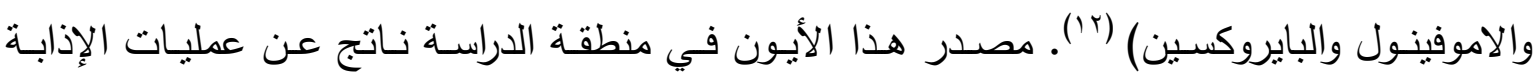

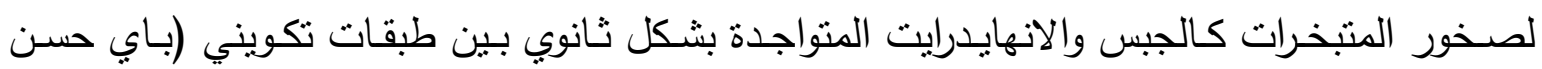

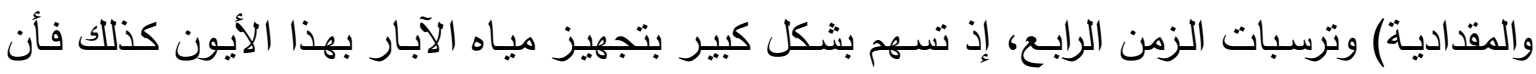

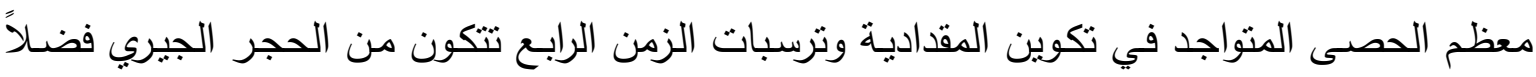

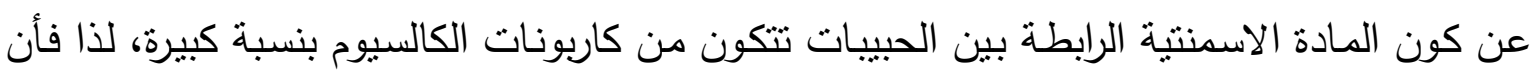

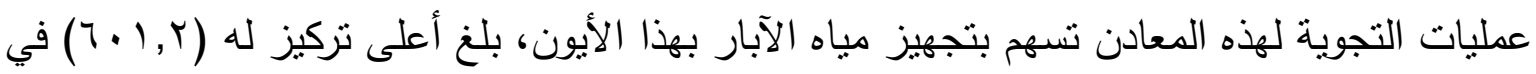

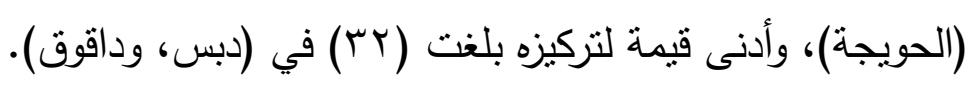

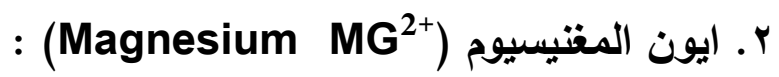

تُعدُ الصخور (الدولوماتية) من المصادر الأساسية لـ(أيون المغنيسيوم) فضلاً عن المعادن الحاوية

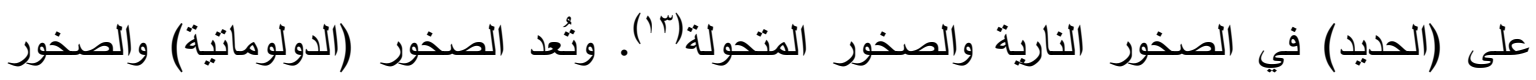
(الجيرية) المصدر الرئيس لأيون المغنيسيوم في منطقة الدراسة، إذ تتعرض الصنية الصنور (الدولوماتية)

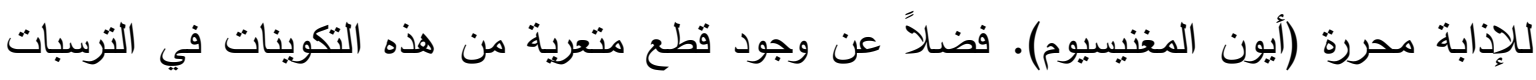

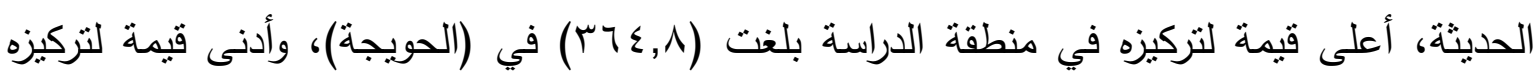
بلغت (9,v) في (دبس، الحويجة، وداقوق).

r. أيون الصوديوم (Sodium $\mathrm{Na}^{+}$

المصدر الأساسيّ لمعظم (أيون الصوديوم) في المياه الطبيعية يرجع إلى المعادن (الطينية)

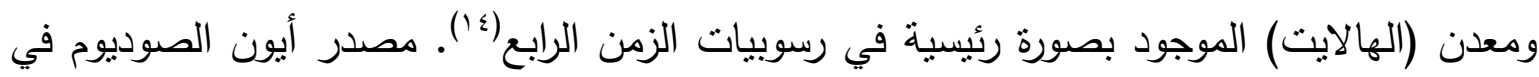

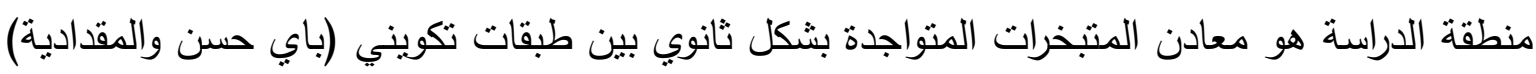

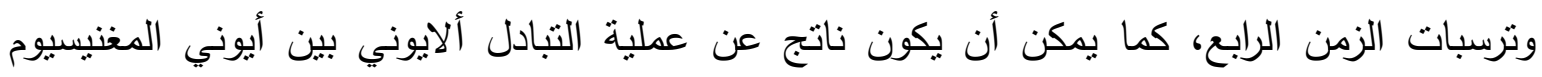

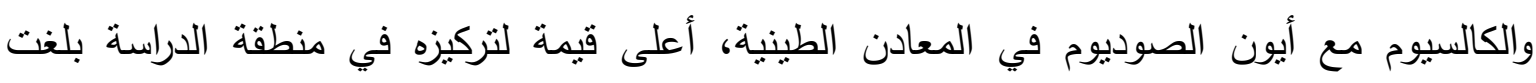

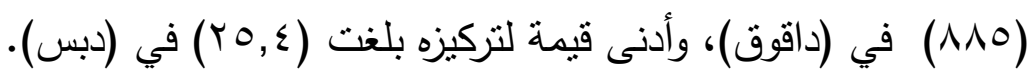


ع. أيون البوتاسيوم (Potassium k) إن مصادر (أيون البوتاسيوم) هي (الاورثوكليس والمايكروكلاين والمايكا والسلفايت) وصخور (المتبخرات)، وجوده متقارب من وجود (أيون الصوديوم) في القشرة الأرضية. لكن نركيز (أيون

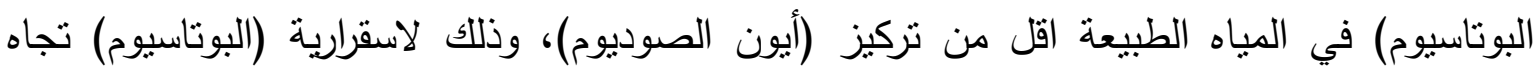

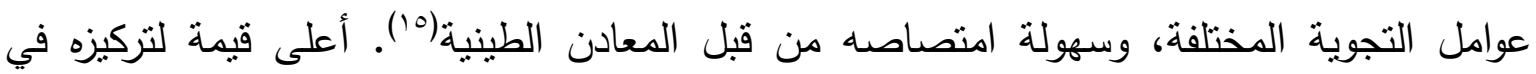

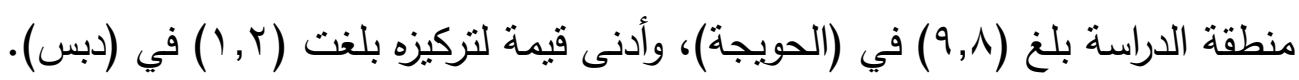

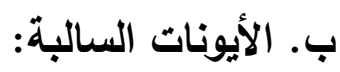
ا.أيون الكلوريد (Chloride $\mathrm{Cl}^{-}$ إن نركيز (أيون الكلوريد) في المياه يعد مقياسا لارجة ملوحتها، ولكونه من الأيونات المستقرة في

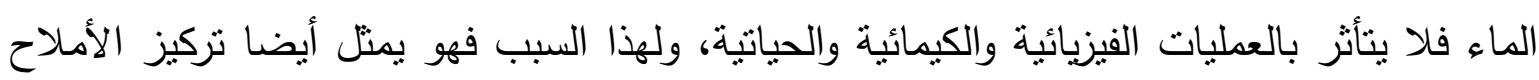
الذائبة الكلية ويتاسب معها تتاسبا طرديا. واهم مصادره في المياه الجوفية ترسبات المتبخرات

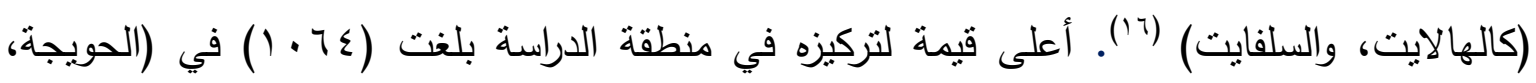

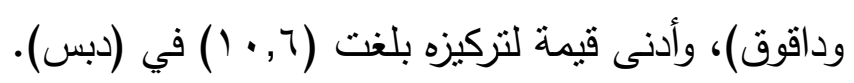

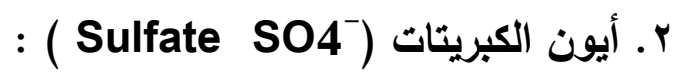

إن المصدر الرئيس (للكبريتات) في المياه هي التجوية الكيمبائية للصخور الحاوية على صخور

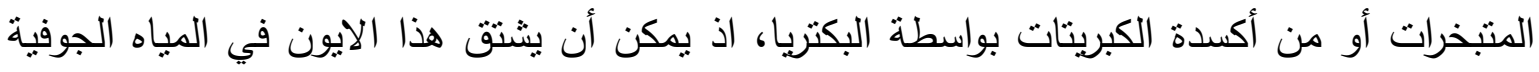

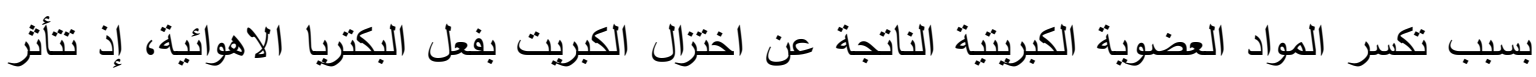

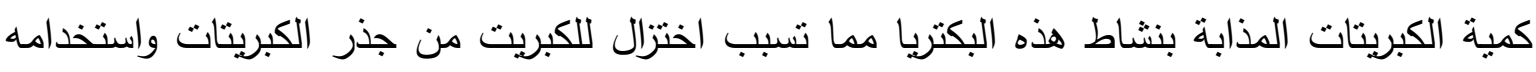

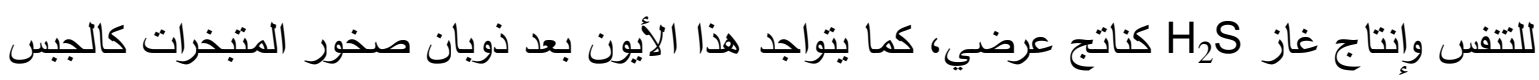

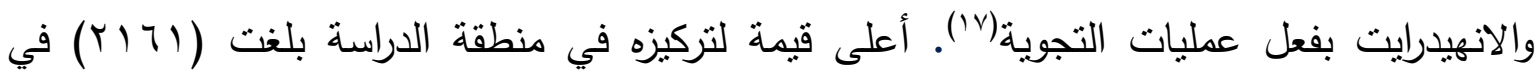

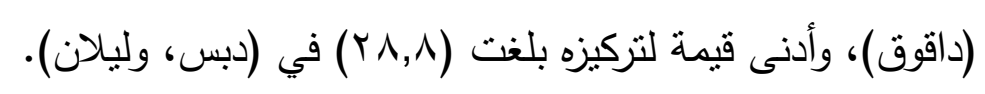

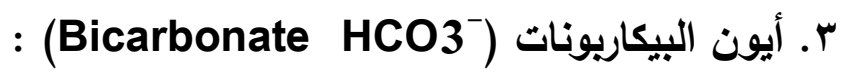

تعُد مصدراً رئيساً لقلوية المياه، تتنأ البيكاربونات نتيجة لنشاط عمليات إذابة للصخور الجيرية.

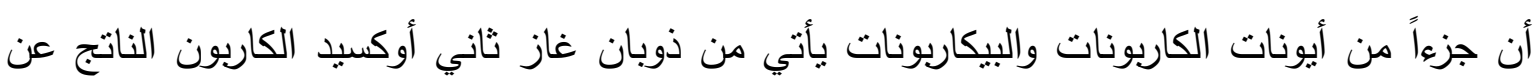

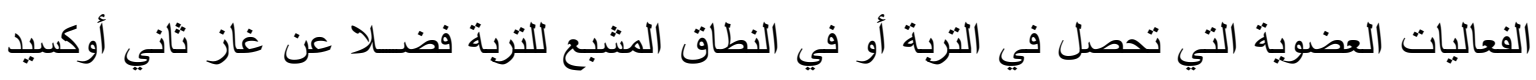

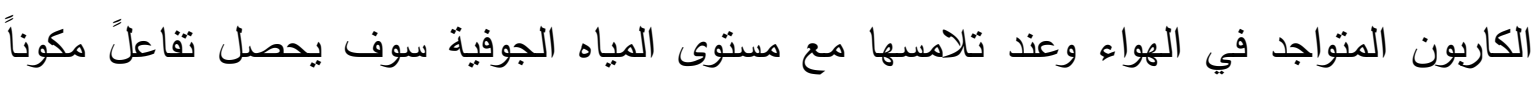

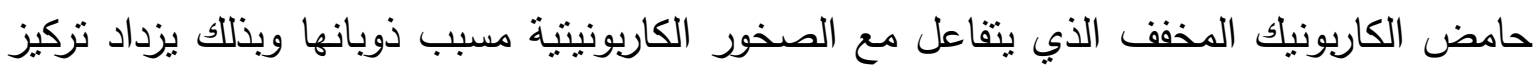
نسبة أيونات الكاربونات والبيكاربونات في المياه الجوفية(^). أعلى قيمة لتركيزه في منطقة الدراسة الدية

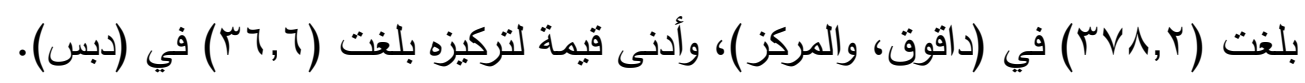




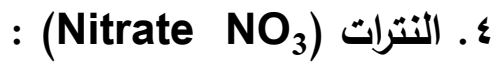

مصادر النترات في المياه الجوفية ناتجة عن عدة أسباب أهمها أكسدة النتروجين المرتبط عضويا

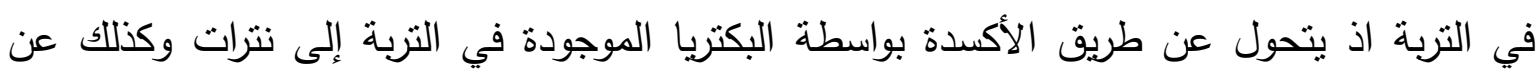
طريق التسميد المتكرر سواء كان بالسماد الطبيعي أو الكيميائي فقد يسهم بشكل فعال في زيادة لتركيز

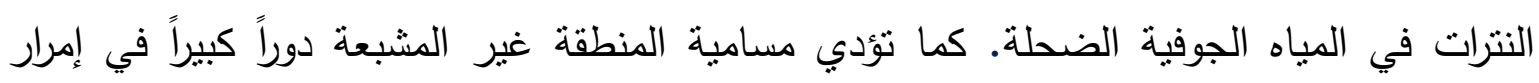
أثنكال النتروجين إلى المياه الجوفية. نواجد هذا الايون يقلل من استخدام الأسدة النايتزوجينية وبالتالي

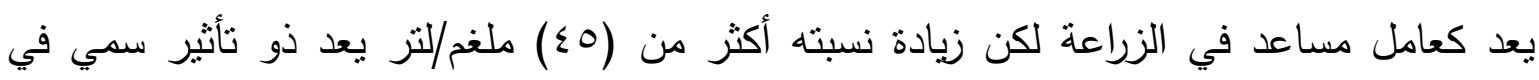

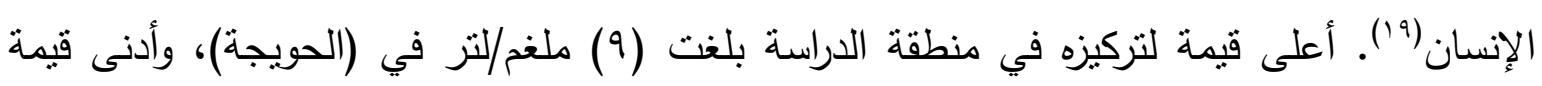
لتركيزه بلغت (9 ( · ) ملغم/لتر في (دبس). المبحث الثالث: صلاحية المياه الجوفية للاستعمالات المختلفة في منطقة الاراسة 1. صلاحية المياه الجوفية لشرب الإنسان:

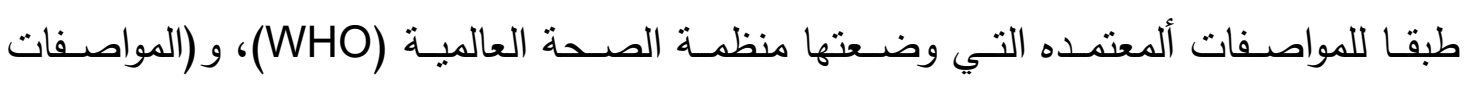

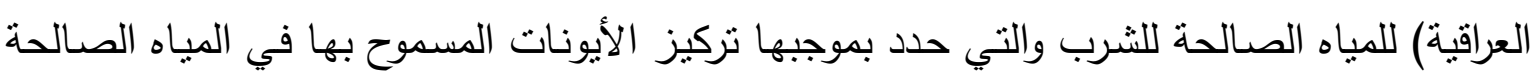

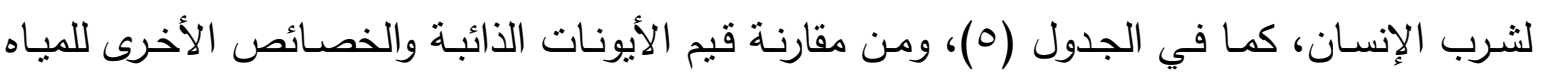

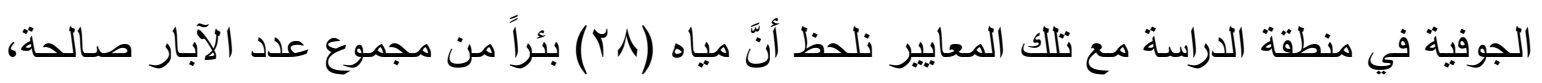

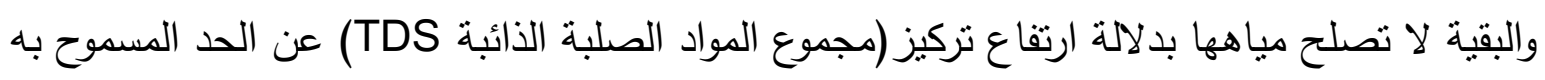

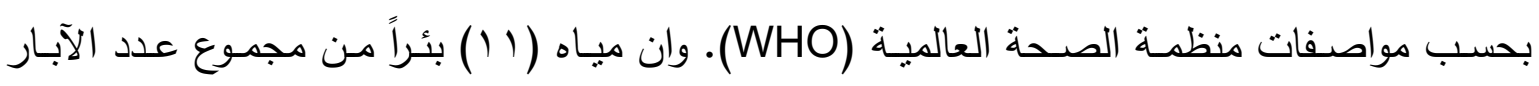

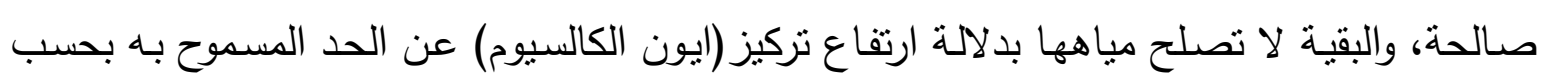
المواصفات العراقية المعتمدة. 
جدول (•)

مواصفات منظمة الصحة العالمية والعراقية للمياه الصالحة للشرب

\begin{tabular}{|c|c|c|}
\hline المواصفات العراقية & who مواصفات هيئة الصحة العالمية & الخاصية \\
\hline $1.0-7.0$ & $1.0-7.0$ & ألأس الهيدروجيني Ph \\
\hline $1 \ldots$ & $1 \ldots$ & TDS مجوع المواد الصلبة الذائبة \\
\hline ir & ir & البوتاسيوم K \\
\hline r.. & $r$. & الصوديوم Na \\
\hline ๑. & iro & المغتيسيوم Mg \\
\hline 0. & vo & الكالسيوم Ca \\
\hline ro. & ro. & الكلوريدات CI \\
\hline ro. & ro. & الكبريتات So \\
\hline ro. & ro. & البيكاريونات \\
\hline o. & o. & النترات No \\
\hline
\end{tabular}

المصدر: المنمي، دياري علي محمد أمين، دراسة كيميائية وبيئية للمياه الجوفية في مدينة السليمانية وضواحيها، رسالة

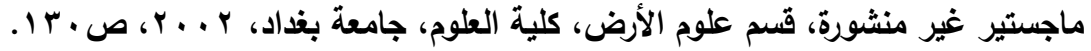

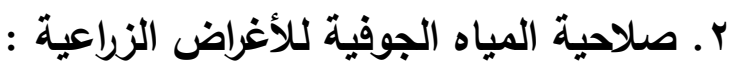

من المتغيرات المهمة التي تحدد نوعية المياه لأغراض الري هي (الملوحة أو المواد الصلبة الذائبة الكليـة (TDS) لتأثيرهـا الكبير في التربـة، ومـن ثم تأثيرهـا على النباتات المزروعـة المؤثرة في إنتاج المحاصبل(·r). بالاعتمـاد على كمية (المواد الصلبة الذائبة) حسب تصنيف (Train) تصنف المياه الصالحة للري إلى أربعة أصناف، كما يتضح في الجدول (T)، وعند مقارنة قيم (الملوحة الكلية) للمياه الجوفية في الاقضية كما جاءت في الجدول (ع)، مع تلك الأصناف، يظهر لنا إن مياه (V) بئراً، بنسبة (r \% \%) تصنف ضـمن المياه (الصـالحة) لاستخدامها في الري ولا تسبب تأثثرات ضـارة لان مجموع أملاحها اقل من ( . (0) ج/ م/ م، وإن مياه (^) آبار ، بنسبة (0 (\%) تصنف ضمن المياه (التي قد يسبب استخدامها تأثيرات ضـارة على المحاصيل الحساسـة جدا للملوحة) لان قيم مجموع

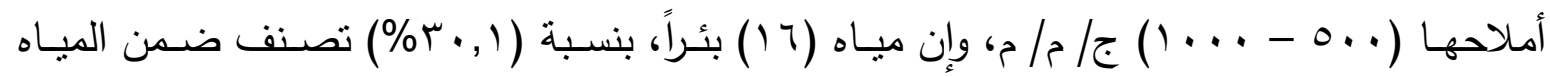
(التي قد تسبب تأثثرات ضارة لكثير من المحاصبل لذلك استخدامها بحتاج إلى خبرة) لان قيم مجموع

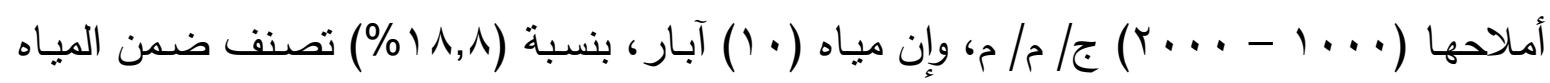
(التي يمكن استخدامها لري النباتات العالية التحمل للملوحة واستخدامها يحتاج إلى الخبرة) لان قيم

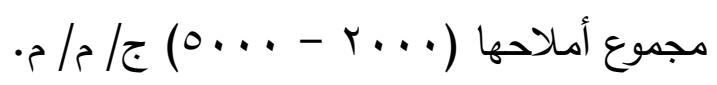


جدول (†)

تصنيف المياه للري حسب كمية ملوحتها

\begin{tabular}{|c|c|}
\hline مواصفات المياه & مجموع المواد الصلبة الذائبة TDS \\
\hline استخدامها للري لا يسبب تأثثرات ضارة & o.. \\
\hline استخدامها قد يسبب نأثيرات ضارة على المحاصيل الحساسة جدا للملوحة & $1 \ldots-0 \ldots$ \\
\hline قد بسبب تأثثرات ضارة لكثير من المحاصيل لذلك استخدامها يحتاج إلى خبرة & $r \ldots-1 \ldots$ \\
\hline يمكن استخدامها لري النباتات العالية التحمل للملوحة واستخدامها بحتاج إلى الخبرة & $0 \ldots-r \ldots$ \\
\hline
\end{tabular}

Reference: Train R/ E, Quality Criteria for water, castle house publication,Ltd, 1979, p256.

\section{r. صلاحية المياه الجوفية لأغراض الاستهلاك الحيواني :}

أن هناك مواصفات معتمدة من قبل (Altoviski) للمياه الصالحة لأغراض الاستهلاك الحيواني، كمـا في الجدول (V)، وعند مقارنتها مـع مواصفات المياه الجوفيـة في منطقة الدراسـة نجد إن مياه جميع الآبار تصنف ضمن فئتي المياه (الجيدة جداً) و (الجيدة) للاستهلاك الحيواني.

جاول (v) (1)

مواصفات المياه للاستهلاك الحيواني

\begin{tabular}{|c|c|c|c|c|c|}
\hline الحد الأعلى & مياه يمكن استخدامها & مياه مسموح استخدامها & مياه جيدة & مياه جيدة جدا & تركيز الأيونات \\
\hline$\{\ldots$ & ro.. & r... & $10 .$. & $\wedge \ldots$ & الصوديوم \\
\hline $1 \ldots$ & $9 \ldots$ & $\wedge .$. & $v \ldots$ & ro. & الكالسيوم \\
\hline$v \ldots$ & 7. & o.. & ro. & 10. & المغتيسيوم \\
\hline $7 \ldots$ & $\{\ldots$ & $r \ldots$ & r... & $9 \ldots$ & الكلوريدات \\
\hline $10 \ldots$ & $1 \ldots$ & $v \ldots$ & $0 .$. & $r \ldots$ & الملوحة \\
\hline
\end{tabular}

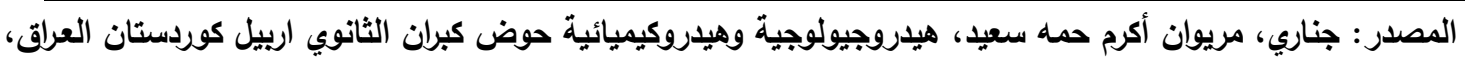

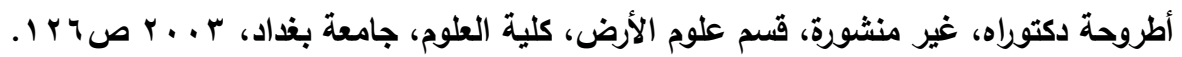
ع ـ صلاحية المياه الجوفية للأغراض الصناعية :

إنَّ استخدام الميـاه للأغراض الصـناعية المختلفـة تتطلب مباهـاً ذات مواصـفات، فلكل صـناعة مواصفاتها الخاصـة بها، والخلل في مواصفات المياه المستخدمة ينعكس على نوعيـة الإنتاج لتلك الصناعة، فعلى سبيل المثال تستخدم الحدود القياسية المسموح بها لثرب الإنسـان كحدود صـالحه لاستخدامها في الصناعات التي يدخل الماء في منتجاتها مثل (معامل المياه المعدنية والمياه الغازية وصناعة التلج ومعامل تعليب المواد الغذائية)، في حين تحتاج صناعة الأدويـة إلى حدود اقل من الحدود المسموح بها لشرب الإنسان، كما أن بعض الصناعات لا يدخل الماء في منتجاتها وإنما يكون 
عامل مسـاعد في هذه الصناعات مثل (معامل الغزل والنسيج والمصـافي النفطية ومعامل البلاستلك وصناعة الورق والتعدين وصناعة الجلود والصناعات الكيماوية). بالاعتماد على المواصفات القياسية للمياه المستعملة في الأغراض الصناعية، كما في الجدول (^) ومن خلال مقارنة الخصائص النوعية للمياه الجوفيـة في منطقة الدراسـة مـع هذه المواصفات نلاحظ بـان مياه (r (Y) بئراً من مجموع عدد الآبار تصلح لصناعة (التعليب والمشروبات) والبقية لا تصلح مياهها للصناعة بدلالة ارتفاع تركيز (ايون الكالسيوم) عن الحد المسموح به.

ومياه (IV) بئراً من مجموع عدد الآبار تصلح لصناعة (الفاكهة المعلبة)، أما البقية؛ فإنَّ مياهها

لا تصلح ا للصناعة بدلالة ارتفاع تركيز (مجموع المواد الصلبة الذائبة TDS) عن الحد المسموح به. ومياه ( (Y) بئراً مـن مجموع عدد الآبـار تصلح لصناعة (المنتجـات النفطيـة)، أمـا البقيـة؛ فإنّّ مياهها لا تصلح ا للصناعة بدلالة ارتفاع تركيز (ايون الكالسيوم) عن الحد المسموح به.

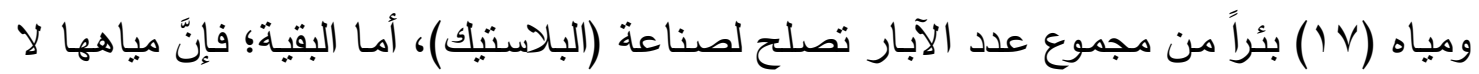
تصلح اللصناعة بدلالة ارتفاع تركيز (ايون المغنيسيوم) عن الحد المسموح به.

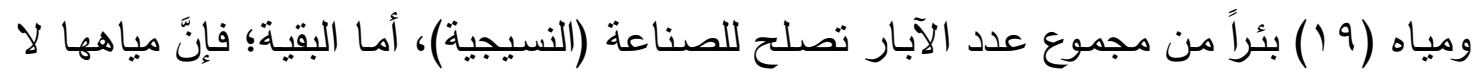
تصلح ا للصناعة بدلالة ارتفاع تركيز (ايون المغنيسيوم) عن الحد المسموح به. جميـع مبـاه الآبـار فـي منطقة الدراسـة لا تصـلح لصـناعتي (الـورق والجلـود) بدلالـة ارتفـاع تركيز (ايون الكالسيوم) و (ايون الهيدروجين) عن الحد المسموح به. ومياه (1 ( ) بئرراً من مجموع عدد الآبار تصلح لصناعة (الاسمنت)، أما البقية؛ فإنّ مياهها لا لائل تصلح اللصناعة بدلالة ارتفاع تزكيز(مجموع المواد الصلبة الذائبة TDS) عن الحد المسموح به. جدول (^) (1)

مواصفات المياه للأغراض الصناعية

\begin{tabular}{|c|c|c|c|c|c|}
\hline الكالسيوم & المغنيسيوم & الكلوريدات & مجموع المواد الصلبة الذائبة & درجة نركيز ايون & نوع الصناعة \\
\hline \multirow[t]{2}{*}{$1 \cdots$} & & $0 .$. & & 1.0.7.0 & التعليب والمشروبات \\
\hline & & ro. & $0 .$. & $1.0-1.0$ & الفاكهة المعلبة \\
\hline vo & & r... & $1 \ldots$ & $9-1$ & المنتجات النفطية \\
\hline$\wedge$. & די & & & N.r -7.0 & البلاستيك \\
\hline $1 \ldots$ & 0. & $0 .$. & $1 \ldots$ & $1-7.0$ & النسيجية \\
\hline \multirow[t]{3}{*}{ r. } & ir & $r \ldots$ & $1 \ldots$ & $1 \cdot-1$ & الورق المقصور وغير المقصور \\
\hline & & ro. & - & $\wedge-1$ & الجلود \\
\hline & & ro. & $7 .$. & $1.0-1.0$ & الإسمنت \\
\hline
\end{tabular}

Reference: Hem J.D, Study \& interpretation of the chemical characteristics of natural water, USGS, Water supply paper, P263. 
هـ صلاحية المياه الجوفية لأغراض البناء والإنشاءات:

لمعرفة مدى صسلاحية المياه الجوفية في منطقة الدراسـة لأغراض البناء والإنشاءات تم استخدام تصنيف (Altoviski)، كما في الجدول (9)، ومن خلال مقارنة الخصائص النوعية للمياه الجوفية في منطقة الدراسة مع هذه المواصفات نلاحظ بان اغلب مباه الآبار صالحة لأغراض البناء والإنشاءات، فمياه (\&V) بئراً من مجموع عدد الآبار (T) بئر تصلح، ذلك يعني إن (T) آبار مياهها لا تصلح لأغراض البناء بدلالة ارتفاع تركيز (ايون الكالسيوم) و(ايون المغنيسيوم) عن الحد المسموح به.

جدول (a)

صلاحية المياه لإغراض البناء والإنشاءات

\begin{tabular}{|c|c|}
\hline الحد المسموح & تركيز الأيونات ج/م/م \\
\hline 117 & الصوديوم \\
\hline$\varepsilon r V$ & الكالسيوم \\
\hline FV. & المغتيسيوم \\
\hline rIAV & الكلوريدات \\
\hline
\end{tabular}

المصدر :المنمي، دياري علي محمد أمين، دراسة كيميائية وبيئية للمياه الجوفية في مدينة السليمانية وضواحيها، رسالة

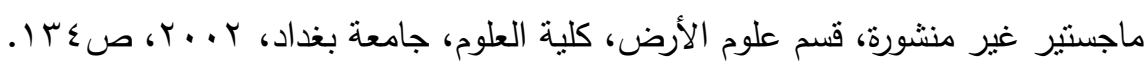

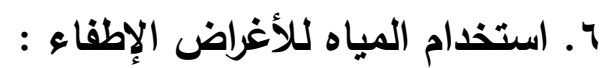

لا تحتاج عمليات الإطفاء إلى معايير أو مقاييس محدده، لذا يمكن استخدام المياه الجوفية لهذا الغـرض بغض النظر عن قيم تركيز الايونـات، ولاسـيما في المنـاطق البعيدة عن مصـادر الميـاه السطحية، كمـا يمكن استخدام الميـاه الجوفيـة لزيـادة كفاءة أنظمـة الإطفاء في المشـاريع الصـناعية الضخمة من خلال إنشاء منظومة من مضخات تعمل بالطاقة الكهربائية، كما يمكن إنشاء مثل هذه المنظومات في معسكرات الجيش والمطارات والبنايات المهمة التي تحتاج إلى عمليات إطفاء سريعة مثل المخازن وغيرها. الاستتناجات :

من خلال نتائج تحاليل الخصائص النوعية لعينات الآبار في منطقة الدراسة نلاحظ التالي: ا ـ التباين المكاني الكبير لتراكيز الخصائص النوعية للمياه الجوفية في منطقة الدراسة. r. إن اغلب نسب التراكيز العالية للخصاص النوعيـة تقع في قضـاء (الحويجة، داقوق، والمركز ). بحيث إن أغلبية المياه الجوفية لآبار تلك الأقضية يتجاوز تركيز خصائصها النوعية الحدود المسموح بها لأغلب مجـالات الاستعمالات المختلفة على العكس من ذلك نجد إن أغلبيـة الآبـار الصـالحة للاستعمالات المختلفة تقع في قضائي (دبس، وليلان). ع. لا يوجد في منطقة الدراسة جهات مختصـة تأخذ على عاتقها وبصوره جديه مسألة استثمار المياه الجوفية لحل أزمة شح المياه. 
ا ـ ترشيد استعمال المياه والمحافظة عليها من خلال وضع ساعات مراقبة على الآبار لتنظيم كمية

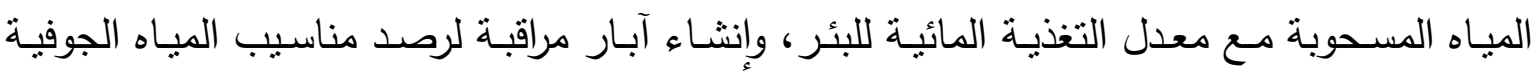

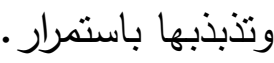
r. إبداء التوجيهات العلمية الدقيقة للمزارعين فيما يخص زراعة الدحاصيل التي تلائم نوعية المياه

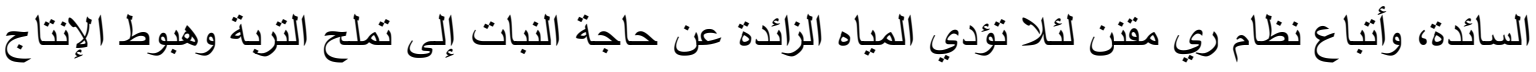
الزراعي فضلاً عن نضوب مياه الآبار .

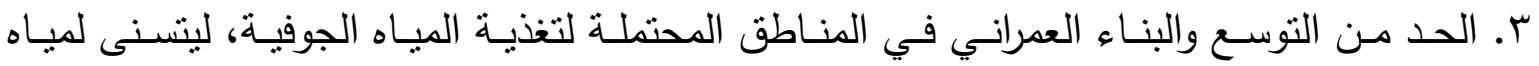
الأمطار والمياه السطحية من إدامة الخزين الجوفي. ع. تنتغيل كل الآبار الحديثة التي تم حفرها في القرى بشكل منظم، وعدم التركيز على آبار محددة وترك أخرى، وذلك للمحافظة على الخزين المائي لكل الآبار . 
* تم الاستعانة ب(الهيئة العامة للمياه الجوفية) إحدى تشكيلات وزارة الموارد المائية، في الحصول على نتائج تحليل الخصائص النوعية لنماذج (VV) بئر للمياه الجوفية، موزعة على مواقع منتوعة في منطقة الدراسة.

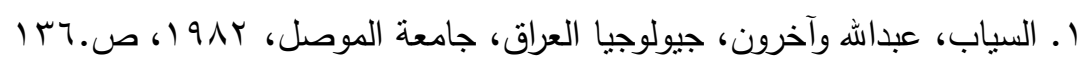

Y. العمري، فاروق صنع اله و علي صادق، جيولوجية شمال العراق، مؤسسة دار الكتب، جامعة الموصل، I9VV، .

3. A.M.Barwary, \& N.A. Slewa, the Geology of Khanaqin Quadrangle, Sheet (NI-38-7), Scale 1:250000, GEOSURV, Baghdad, 1993, p. 14.

4. Sissakian, V.K, The Geology of Arbeel Quadrangle, Sheet (NJ-38-15), Scale 1:250000, GEOSURV, Baghdad, 1997, P.P. 13- 14.

5. Sissakian, V.K. \& Others, The Geology of Al-Mosul Quadrangle, Sheet (NJ-38-13), Scale 1:250000, GEOSURV, Baghdad, 1995, P.15.

6. Barwary, A. M., \& Slaiwa, N.A, The Geology of Samarra Quadrangle, Sheet (NI-38-6), Scale 1:250000, GEOSURV, Baghdad, 1995, p.22.

7. Buring, P., Soil and Soil Conditions in Iraq, Ministry of Agriculture, Baghdad, 1960, p.78.

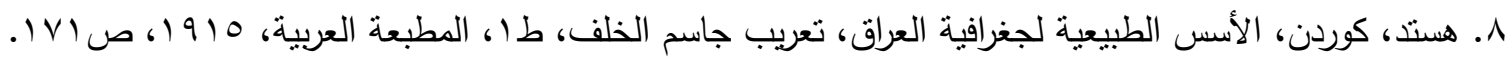
**قيصد به المستوى الذي تستقر عنده المياه الجوفية في الآبار، وهو المنسوب الذي يتعادل فيه الضغط الجوي والضغط الهيدروليكي عند السطح للمياه الجوفية غير المحصورة. المصدر :

David, K, Todd Ground water hydrology U.S.A., 1959, p.150.

(Dynamic water level) *** وهو المسنوى الذي يستقر عنده ماء البئر أثناء الضخ في فترة زمنية معينة. ***** وهي الإنتاجية في وحدة الانخفاض، ويفيدنا في معرفة كمية المياه الممكن استغلالها في الطبقة الحاملة للمياه. ويتم استخراجها من تطبيق المعادلة (D.D/Q) حيث Q تمنل الإنتاجية، D.D تمنل الانخفاض الحاصل في منسوب ماء البئر أثثاء الضخ. 9. وزارة الموارد المائية، الهيئة العامة للمياه الجوفية / قسم إدارة المياه الجوفية، تقارير غير منشوره، ^ . . ؟. • ا. بيتز ، س. مثلاند، بيولوجية المياه العذبة، ترجمة، حميد سليمان خميس و محمد حامد أبوب، مطبعة التعليم

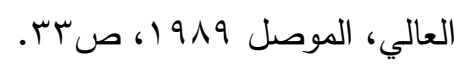

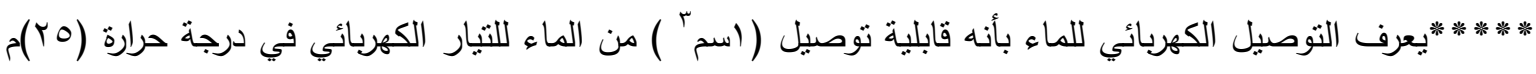
وتقاس بوحدات مايكروموز/سم المصدر:

Hem, J, D, Study and interpretation of the Chemical characteristics of natural water USGS, water Sapp, p.225-263.

الـ بابا شيخ، سردار محمد رضا، هيدروجيوكيميائية مياه الكهوف والعيون في منطقة (سنكاو ـ جمجمال) محافظة

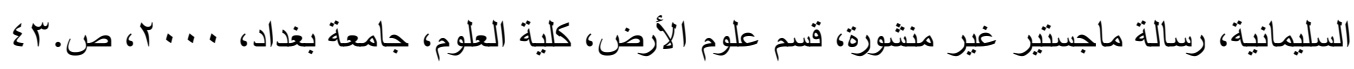


זا . جناري، مريوان إكرام حمه سعيد، هيدروجيولوجية وهيدروكيمائية حوض كه يران الثانوي اربيل كردستان العراق،

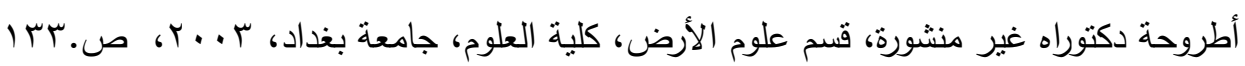

r 1 . بابا شيخ، سردار محمد رضا، مصدر سابق، ص. ع ا. حسين، يحيى عباس، الينابيع المائية بين كبيسة والسماوة واستثماراتها، أطروحة دكتوراه غير منشورة، قسم

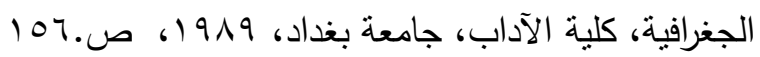
0 ـ جناري، مريوان إكرام حمه سعيد، مصدر سابق، ص.0با 17 ا ـ بابا شيخ، سردار محد رضا، مصدر سابق، صلهم. V ا ـ اليازجي، ياسر ميسر وحازم جمعة محمود، دراسة الخصائص النوعية والعناصر الأثرية لمياه نهر دجلة في مدينة

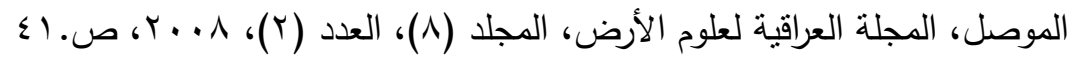

11) المصدر نفسه ، ص.|؟ 9 ا ـ وزارة الموارد المائية، الهيئة العامة للمياه الجوفية / قسم إدارة المياه الجوفية، تقارير غير منشوره، م . . ؟. •r. الثبلاق، محمد منصور وعماد عبد الطيف، الهيدروجيولوجيا التطبيقية، منشورات جامعة عمر المختار، البيضاء، (77) 


\title{
Study the characteristics of quality of groundwater in the province of Kirkuk and ways to invest \\ M. Dr. Wasn Mohammad Ali Kazem / Mustansiriya University M. M. Nagham Mansour / University of Baghdad
}

\begin{abstract}
:
The study is based on the results of analyzes of characteristics qualitative models (57) wells drilled in the study area, the amount of the concentrations of those characteristics and geographical distribution in the province of Kirkuk and the possibility of investing in multiple areas of the statement, showing from which most of the concentrations and high levels located in the district (Hawija, Daquq, and Center). So that the majority of the groundwater wells that districts exceed the concentrations characteristics qualitative limits for most of the different areas on the contrary, we find that the majority of valid wells for various uses located in (Dbass \& Lelan), because of the qualitative characteristics that fall within the permitted for those uses border. This is due to the geological formations to those areas containing materials (lime and limestone), such as stone (limestone, dolomite, gypsum). Also played a geological characteristics have an important role in determining the amount of groundwater, covering the study area geological formations consisting of sedimentary rocks consisting mostly of gravel, sand and characterized by permeability rocks allows water access during and formation water tanks inside those rocks.
\end{abstract}

